\title{
Initial Calibrations and Wind Tunnel Test Results for an In-Flow Reference Array using New In-Flow Acoustic Sources in Four Array Mount Configurations
}

\author{
Clifton Horne* and Nathan Burnside** \\ NASA Ames Research Center \\ Moffett Field, CA USA
}

\begin{abstract}
Summary
This paper describes efforts to develop a small in-flow phased microphone array as a reference acoustic sensor and quantify its level-measurement accuracy with new in-flow calibration sources. The devices can be applied to a wide variety of in- and out-of-flow measurement applications and test facilities. Recent tests of the array and two calibration sources in the NASA Anechoic Chamber and Army 7- by 10-ft Wind Tunnel at NASA Ames Research Center demonstrated that the array was functional over a frequency range of 2 to $100 \mathrm{kHz}$ for emission angles of $92^{\circ}, 108^{\circ}$, and $120^{\circ}$, and Mach numbers of $0,0.15$, and 0.25 . The array and calibration sources were then used to assess the relative effects of array installation on background noise and level measurement accuracy by locating the array in the flow (strut- and wall-mounted) as well as outside the flow behind a porous wall screen and a free shear layer. The wind tunnel array measurements were compared with anechoic chamber measurements using discrete microphones at the same source distance and emission angles. At $92^{\circ}$, the noise floor and attenuation spectra were comparable (within $5 \mathrm{~dB}$ ) for each installation from 2 to $30 \mathrm{kHz}$. At higher angles, the array installation behind the Kevlar screen had the lowest noise floor at $\mathrm{M}=0.15$ and 0.25 . The array installation 10" (maximum available distance) behind a free shear layer had higher background noise that is typically reduced to a lower level by moving the array back further from the flow. For emission angles greater than $92^{\circ}$, both the Kevlar and free shear layer installations exhibited stronger attenuations in measured level, beginning at lower frequencies than either the wallor strut mount configurations. Additional array and calibration source units of the same design are being tested at NASA's Glenn Research Center and Langley Research Center in their aeroacoustic research facilities in an effort to improve measurement accuracy and repeatability.
\end{abstract}

\section{Background}

Microphone arrays have been used extensively for more than two decades to quantify the location and levels of aircraft related noise sources in open- and closed- test section wind tunnels. Relative to single microphone sensors, arrays can improve the dynamic range by significantly suppressing background noise associated with wind tunnel fan drives, flow noise over the array (for in-flow arrays), and noise from model and sensor support struts in the flow. The arrays are generally designed to meet the requirements of each facility and are often modified for succeeding tests. Facility-specific calibration methods have also been developed to quantify the accuracy of array measurements, sources of signal contamination, and minimum measurable source levels. Although confidence in measurements from a particular facility or test can be gained from a rigorous program of in-situ calibrations and validations, it remains problematic to directly compare measurements obtained from different facilities and array installations due to the differences in array design and processing methods. These comparisons could be expedited with the availability of both reference array sensors and in-flow calibration sources that have wide frequency range and repeatable sensitivity and source output levels.

Arrays for measurement of non-axisymmetric aeroacoustic sources generally consist of a distribution of microphones over a surface of finite area. Arrays designed for high spatial resolution may have a relatively large capture angle that averages the response over a moderate to large portion of the source directional field. Improved level-measurement accuracy can be achieved at the expense of spatial resolution by confining the microphones to an area that results in a small capture angle, typically $5-10^{\circ}$. A smaller pattern also minimizes the level sensing errors due to loss of coherence between widely spaced sensors in the measurement of extended sources. This concept was the basis for a series of out-of-flow array designs by Humphreys, et al for obtaining high-accuracy level measurements in the open jet flow facilities at NASA Langley Research Center ${ }^{1}$.

* Associate Fellow, Aerospace Engineer

** Senior Member, Aerospace Engineer

The SADA/MADA arrays from that effort used a 33-element open frame array 8 inches in diameter with microphone shading to maintain a constant beam width over the design frequency range. In the present study of in- 
flow arrays, we used an 8 in. diameter, 24-element array without microphone shading in order to sustain suppression of uncorrelated sensor noise by preserving the full count of microphones. A second array plate with 33 microphones in the same locations as the SADA array was built to enable direct comparisons with the that array.

Aeroacoustic research in closed test section wind tunnels has been conducted with either strut- or wall- mounted inflow arrays $\mathrm{s}^{2,3}$. Relative to out-of-flow arrays, such sensors are subject to hydrodynamic noise from an energetic boundary layer over the sensing surface. As a consequence, a variety of passive and processing methods have been applied to mitigate this noise source and improve dynamic range, including recessing the array plate behind a porous wind screen ${ }^{4,5,6,7}$ and cross-spectral matrix background noise subtraction ${ }^{8,9}$. For arrays placed either in or out of the flow, turbulence in the shear- or boundary-layer between the source and array, scatters sound from the target source, leading to measurement errors that grow with frequency, shear layer thickness, and turbulence level ${ }^{10,11}$.

One goal of the present study was to further develop methods of achieving acoustic source level measurements of high accuracy and dynamic range over a broad frequency range with an in-flow array. This effort required the development of new in-flow reference sources for calibration. The array and sources were used in a comparative assessment of background array level measurement accuracy of four typical configurations with the same array: a strut-mounted array, a wall-mounted in-flow array, and an out-of-flow array mounted behind a porous Kevlar screen in the tunnel wall, and an array mounted outside of the free shear layer of an open jet tunnel.

Another goal of the current effort was to develop a common design for a small in-flow array and in-flow calibration sources that will be used to improve the aeroacoustic research capabilities at NASA's Ames, Glenn, and Langley Research Centers. This program, currently in progress, was initiated by building identical microphone arrays, fairings, and acoustic source modules as described in this report for use at each center.

\section{Experimental set-up}

Fig. 1 shows the in-flow fairings that housed the microphone array plate and two calibration source modules. The fairings measured $21 \mathrm{in.} \mathrm{long} \mathrm{by} 14 \mathrm{in}$. wide, and either 2 or $3 \mathrm{in}$. thick as needed, and were built as single structures from stereo lithography sintering(SLS) using glass-filled nylon. The SLS fairing was attached to a rigid internal load bearing structure comprised of aluminum plates and steel spacers. The array plate held 24 GRAS 40BF condenser microphones in an 8 in. diameter 3 -armed spiral. The array and fairing are described in Ref. 2 , where it was tested to M 0.3 with acoustic response from 1 to $50 \mathrm{kHz}$. Microphone coordinates are given in Table 1, at the end of the paper. For this study, the array plate was positioned 0.5 in. behind a porous stainless-steel screen that had 325 threads/in. and a flow resistance of 2.8 cgs Rayls. This screen material was selected as optimal from a variety of materials $\mathrm{s}^{12}$ and replaced the $1.5 \mathrm{oz} / \mathrm{yard}$ Kevlar screen (15 cgs Rayls resistance) that was used in previous designs. The Kevlar material produced added noise at frequencies above $15 \mathrm{kHz}$ as well as standing-wave resonances on the order of a few $\mathrm{dB}$ in previous tests. Studies to determine the optimal wind-screen material and density are in progress.

The same fairing was used to house two interchangeable source modules, comprised of either a pair of tweeters that output a maximum of 25 watts from 0.8 to $40 \mathrm{kHz}$, or a 2 in. diam. hemispheric multi-jet source (airball) operated with compressed air. The latter source was derived from an omnidirectional source that has been used previously in anechoic chambers at NASA. The device in this study had forty-four 0.035 in. diam. holes in the hemisphere facing the flow. The ball was enclosed by a hemispheric course screen to enhance low frequency noise and reduce direct impingement of the microjets on the windscreen. By placing the acoustic source, pressure, and temperature sensors in the fairing behind the porous screen, the source was isolated from direct flow effects and the properties of the air supply to the source could be accurately measured. For this report, only the airball measurements will be presented.

The array data were acquired with National Instruments PXI based 24-bit A/D with a sample rate of $204 \mathrm{kSamp} / \mathrm{sec}$. Array data was processed using Beamform Interactive software from Optinav. Results presented in this report are conventional delay-and-sum beamforming peak levels, without cross-spectral-background noise subtraction ${ }^{8,9}$. 
Fig. 2 shows the calibration set-up in the 25- by 18- by 11-ft high NASA Ames anechoic chamber. The source fairing was placed on a motor-driven turntable and positioned for measurements for emission angles $\theta$ of $0^{\circ}$ to $180^{\circ}$ in $5^{\circ}$ increments, with $0^{\circ}$ emission upstream. The acoustic field was measured at a radius of $48 \mathrm{in}$. with either the 8 in. diameter array plate in its fairing, or by a fixed microphone stand with seven GRAS $40 \mathrm{BF}$ 1/4" diameter condenser microphones, positioned at azimuth angles $\psi$ of $0^{\circ},+/-11.25^{\circ},+/-22.5^{\circ}$, and $+/-45^{\circ}$. For linearity comparisons, the $0^{\circ}$ azimuthal microphone was also repositioned to a 24 in. radius for select measurements.

Fig. 3 presents contour maps of the directional sound pressure field in decibels of the airball source fairing in selected $1 / 3^{\text {rd }}$-octave bands from 2 to $64 \mathrm{kHz}$, as surveyed by the fixed microphones in the anechoic chamber at a radius of $48 \mathrm{in}$. and a nominal supply pressure of $17 \mathrm{psig}$. The maximum level is close to broadside emission angle $\theta^{\prime}$ of $90^{\circ}$ and azimuth angle $\psi$ of $0^{\circ}$. The source field became louder and less directional with higher frequencies. In contrast, the tweeter directional field with white noise input (not shown) had a nearly constant peak level over the bandwidth of $800 \mathrm{~Hz}$ to $40 \mathrm{kHz}$, becoming more directional with increasing frequency.

Fig. 4 shows the test placements of the array in the wind tunnel. The array was supported in four configurations: a) on a strut with the screen 12 " from the wall, b) mounted in the wall with the screen 1 in. from the wall, c) array outof-flow with 3 and 5 in. recess behind a porous Kevlar window, and d) array out-of-flow with a 10 in. recess behind the wall plane and free shear layer that filled a $72 \mathrm{in.} \mathrm{long} \mathrm{by} 48$ in. high opening in the wall with a 20 in. diameter half-cylinder collector at the downstream edge of the opening. The wall panel components were modular and quickly reconfigured for rapid configuration changes. For the porous window and free shear layer configurations, a temporary anechoic enclosure was assembled around the opening in the wall to minimize contamination from ambient noise.

The lateral spacing of the array from the source was maintained at 48 in. for each configuration, except for the porous window for which the lateral spacing was set at 41 and 43 in., corresponding the 3 in and 5 in. recess locations respectively. For each configuration, the array response was measured for source emission angles of $92^{\circ}$, $108^{\circ}$, and $120^{\circ}$, Mach numbers of $0,0.15,0.25$, and with 5 source levels for both the tweeter and airball sources. The results have been corrected for microphone plate installation effects, atmospheric absorption, convection, and spherical spreading to a normalized distance of 48 inches. The airball levels should scale with supply air density rather than pressure above the choked flow condition. For this presentation the airball supply temperature was nearly constant through the tests and the supply level will be specified in terms of pressure.

\section{Results and Discussion}

Fig. 5 presents a selection of $1 / 12^{\text {th }}$-octave conventional beamform maps of the source in the wind tunnel at $M=0$ from 1 to $95 \mathrm{kHz}$ and show that both the source and strut-mounted array are both functional over this frequency range. The maps were essentially unchanged with the wind tunnel operating at $M=0.15$, except that the beamform maps below $2 \mathrm{kHz}$ were dominated by facility noise. For a plot dynamic range of $10 \mathrm{~dB}$, no sidelobes were evident in the anechoic chamber over the full frequency range, while some sidelobes of -8 to $-9 \mathrm{~dB}$ below peak were noted in the untreated test section configurations above $40 \mathrm{kHz}$.

Fig. 6 compares the coherence between two closely spaced central microphones ( 1 and 2), and two microphones ( 1 and 24) with wider separation from the anechoic chamber measurement of the tweeter source (left) and airball source (right). Note that the coherence is close to unity over the most of the tweeter frequency range, as expected for a compact coherent source. The corresponding coherence curves for the airball source show that the coherence drops off with increasing microphone spacing and frequency. This behavior is consistent with the airball source comprised of multiple incoherent jets and is typical of realistic aeroacoustic sources such as those from propulsive and airframe noise components. Accurate beamforming is dependent on coherent phase across the array microphones, and coherence levels above approximately 0.20 are compatible with this condition. Panda ${ }^{13}$ reported a method for correcting beamformed levels for sources with low spatial coherence that can be applied to improve accuracy for lower ranges of coherence.

In the discussion that follows, the three array locations are referred to in text by the emission angles at $\mathrm{M}=0.15$ : $92^{\circ}, 108^{\circ}$, and $120^{\circ}$. Fig. 7 compares $1 / 12^{\text {th }}$-octave spectra from the airball source at $100^{\circ}$ emission angle, $0^{\circ}$ azimuth angle, 48 in. radius, $16.5 \mathrm{psig}$ supply pressure, from the anechoic chamber single microphone (green) and the wind tunnel strut mounted array (blue). Spectra for $M=0$ are plotted in the left figure and $M=0.15$ in the right. The spectra from the wind tunnel array conventional beamform peak are within $2 \mathrm{~dB}$ of the corresponding anechoic 
chamber microphone from 2.5 to $30 \mathrm{kHz}$ for $\mathrm{M}=0$, and from 3.5 to $30 \mathrm{kHz}$ for $\mathrm{M}=0.15$. For both spectra, the difference in levels increases to about $5 \mathrm{~dB}$ at $50 \mathrm{kHz}$. The drop off in array response at frequencies above $30 \mathrm{kHz}$ is likely due to reduced source coherence across the array face. Elevated noise levels below $3.5 \mathrm{kHz}$ for $\mathrm{M}=0.15$ are attributed to wind tunnel background noise. This source of contamination can be mitigated with further processing with cross spectral matrix background noise subtraction ${ }^{8,9}$. The effectiveness of this and other advanced processing methods will be considered in a later report.

Fig. 8 presents spectral plots similar to those in Fig. 7 for $125^{\circ}$ emission angle. The anechoic chamber and wind tunnel levels agree to within $2 \mathrm{~dB}$ from 2 to $30 \mathrm{kHz}$ at $\mathrm{M}=0$, and from 5 to $30 \mathrm{kHz}$ at $\mathrm{M}=0.15$, and to within $7-8$ $\mathrm{dB}$ at $50 \mathrm{kHz}$. The drop-out around $3 \mathrm{kHz}$ for the wind-tunnel data was observed occasionally at low frequencies. Fig. 7 and Fig. 8 illustrate the fall-off in airball source level well below the wind tunnel background noise level for frequencies less than 3-4 kHz. This problem is being addressed in follow-on studies by adding lower-frequency sources to the airball fairing.

Fig. 9 compares mean velocity profiles obtained by an $\mathrm{x}$-wire probe above the array screen for each of the four mounting configurations. For the strut, wall, and porous window the boundary layer thicknesses $(90 \%$ of free stream velocity) measured at $\mathrm{M}=0.15$ at the $120^{\circ}$ array positions were 0.3 in., 1.4 in., and 2.3 in. respectively. The free-shear layer thickness between $10 \%$ and $90 \%$ of free stream velocity was greater than 8 in. Note that the component of cross-stream velocity was negligible for each configuration. The velocity profiles above the array screen center at $92^{\circ}, 108^{\circ}$, and $120^{\circ}$ are shown in Fig. 10 (left), and contours of the mean streamwise velocity component of the free shear layer at the $120^{\circ}$ location are shown in Fig 10 (right).

Profiles of turbulent velocity components in the streamwise and cross-stream directions were also measured and were representative of typical fully developed boundary- and shear-layers. The peak measured levels of turbulent components at the $120^{\circ}$ station in the streamwise and wall normal directions were $10.5 \%$ and $8 \%$ for the strut array, $9.5 \%$ and $4.5 \%$ for the wall array, $13 \%$ and $6 \%$ for the Kevlar screen array, and $15 \%$ and $11 \%$ for the free shear layer array.

Fig. 11 presents $1 / 12^{\text {th }}$-octave conventional beamform peak spectra from the four array installations for airball source pressures of $0,1.7,4,8.5$, and $16.5 \mathrm{psig}$, emission angle of $92^{\circ}, \mathrm{M}=0.15$, and lateral source distance of 48 in. for the four array installations. At this emission angle, the strut and wall mount array spectra are comparable below $30 \mathrm{kHz}$. Ripples in the spectra of the array positioned 3 inches behind the Kevlar screen are seen from 3 to 20 $\mathrm{kHz}$, consistent with a low-level standing wave reverberation between the wall screen and array plate. The ripple level can be reduced by setting the array plate to be non-parallel with the wall screen, or by constructing a wall screen of less resistive material such as the 325 -mesh stainless steel screen used for the array screen. The effectiveness of these approaches will be assessed in future tests. Also, of interest is the base noise level for the airball pressure set to zero. At this condition the strut mounted array background noise is around 53-58 $\mathrm{dB}$ above 2 $\mathrm{kHz}$. The background noise levels for the other three installations are somewhat lower: $50-56 \mathrm{~dB}$ for the wall mount, $46-55 \mathrm{~dB}$ for the Kevlar screen with 3 in. recess, and 50-60 dB for the free shear layer. Below $3 \mathrm{kHz}$, the tunnel background noise exceeds the airball source level at all supply pressures. The tone at $2.2 \mathrm{kHz}$ is due to vortex shedding from a 0.25 -inch-thick dynamic pressure probe extending about 12 inches from the forward test section ceiling and was the same peak level of about $86 \mathrm{~dB}$ for each installation. Variations in the tone level with array position in the hard-wall test section are not unexpected and were seen at other Mach numbers. In a later test, this tone was reduced by $20 \mathrm{~dB}$ by wrapping the strut with a spiral of $1 / 8 \mathrm{in}$. wire. Below this frequency, the background noise levels were about $70 \mathrm{~dB}$ at $1 \mathrm{kHz}$ for each configuration, then fell off with increasing frequency except for the strut mounted configuration. Efforts are now in progress to provide effective in-flow calibration source levels down to $300 \mathrm{~Hz}$ by augmenting the airball fairing with a broadband electromechanical driver or by using a broad band compact speaker.

Fig. 12 and Fig. 13 present the source measurement levels at $\mathrm{M}=0.15$ for the emission angles of $108^{\circ}$ and $120^{\circ}$ respectively. For these angles, the background noise of the free shear layer configuration (d) rises dramatically over the full frequency range. This is consistent with background noise associated with hydrodynamic (evanescent) convecting pressure disturbances in the free shear layer. This noise component decays exponentially with distance from the shear layer beyond the 10 inch maximum possible in this test. Since the source pressure level decays as $1 / R$, then the free shear layer signal-to-noise should recover rapidly with greater array distance. For the other configurations, the strut configuration has the highest background noise(a), followed by the wall mount(b), and finally the Kevlar screen 3 in. recess (c). It is also apparent from Fig. 12 and Fig. 13 that the high frequency response of the Kevlar screen (c) and free-shear-layer fall off with frequencies greater than $30 \mathrm{kHz}$ when compared 
to the strut- and wall-mount configurations. Note the wider variation in the $2.2 \mathrm{kHz}$ tone level, from $83 \mathrm{~dB}$ for the strut mount (a) to $90 \mathrm{~dB}$ for the Kevlar screen (c), possibly due to the spatial variations in the reverberant tone field in the hard-wall test section as mentioned previously.

Fig. 14 presents the source measurement levels at $\mathrm{M}=0.25$ for the $92^{\circ}$ array locations. Measurements for the freeshear layer configuration were not obtained at this speed due to unsteady wind tunnel conditions but were acquired up to $\mathrm{M}=0.206$ for comparison with results from other tests. The airball source levels exceed the background noise above $8 \mathrm{kHz}$ for the strut mounted array, and above $6 \mathrm{kHz}$ for the other configurations. The probe tone frequency increased to $3.8 \mathrm{kHz}$ and the peak tone level was about $90 \mathrm{~dB}$ for the three configurations. The conventional beamform peak background noise levels at $1 \mathrm{kHz}$ were 92,88 , and $82 \mathrm{~dB}$ for the strut-mount, wall-mount, and Kevlar screen configurations respectively. Some dropouts in strut-mounted array spectra are seen from 1 to $2 \mathrm{kHz}$.

Fig 15 compares spectra for the four array installations at $\mathrm{M}=0.15$ with the airball source operating at the maximum pressure of $16.5 \mathrm{psig}$, similar to the spectra of Fig. 7 and 8 that compared the measurements from the anechoic chamber to the strut mounted array at $\mathrm{M}=0.15$ and the $92^{\circ}$ location. At $92^{\circ}$, the spectra from the strutand wall-mount configurations are nearly identical. The Kevlar screen and free-shear layer measurements are also similar to each other and to the others from 4 to $40 \mathrm{kHz}$, then fall off by $4 \mathrm{~dB}$ at $90 \mathrm{kHz}$. At $108^{\circ}$ and $120^{\circ}$, the strutand wall mount array measurements are comparable to within $1 \mathrm{~dB}$ from 4 to $90 \mathrm{kHz}$, but the Kevlar screen and free shear layer spectra fall off at a faster rate with frequencies above $20 \mathrm{kHz}$ for $108^{\circ}$ and $15 \mathrm{kHz}$ for $120^{\circ}$. The low frequency free shear layer noise rapidly increases from 1 to $5 \mathrm{kHz}$ at $108^{\circ}$ and from 1 to $8 \mathrm{kHz}$ at $120^{\circ}$ but should also decrease significantly by moving the array further out from the shear layer beyond the $10 \mathrm{in}$. maximum distance available in this study. The high-frequency response roll-off for the Kevlar screen and out of flow arrays could be alleviated by shading the outer array microphones (similar to SADA), or redesigning the array pattern for this application.

Fig. 16 compares spectra for the strut-mount, wall-mount, and Kevlar screen array configurations for the same maximum airball source condition at tunnel Mach number of 0.25 . The probe tone levels at $3.8 \mathrm{kHz}$ are comparable at 90 to $94 \mathrm{~dB}$ for the three configurations. Above this frequency, response of the strut-and wall-mounted arrays are comparable to within 1-2 dB. The Kevlar response (including the probe tone peak) are lower by $2-3 \mathrm{~dB}$ at $92^{\circ}$ and $120^{\circ}$, and by $4-5 \mathrm{~dB}$ at $120^{\circ}$. The consistency of this trend at other source pressures is being analyzed and will be presented in a future report.

\section{Summary}

Initial results from the recent test of a small in-flow array that measured acoustic levels in an anechoic chamber from new reference acoustic sources compare well with single microphone measurements at the same location, and with comparable measurements with the wind-off array mounted in the wind tunnel. The response characteristics and background noise of the 8 in. diameter, 24 element array measured at Mach numbers: $0,0.15$ and 0.25 for four typical aeroacoustic research configurations: mounted in the flow on a strut and on the wall, and out of the flow behind a porous wall screen or a free shear layer in the Army 7- by 10-Ft wind tunnel at NASA Ames. Although tested as a stand-alone sensor, the array size was comparable to the size of the inner pattern of widely-used nested arrays, so these results may apply to those configurations as well. The measurements demonstrated the functionality of the array in measuring source levels from 2 to $100 \mathrm{kHz}$, and the agreement of wind-off acoustic levels measured by the array in the wind tunnel and a single microphone in the anechoic chamber to within $2 \mathrm{~dB}$ from 2.5 to $30 \mathrm{kHz}$ at $\mathrm{M}=0$.

The in-flow calibration source described in this report was a 2 in. diameter hemispheric multi-jet with 440.035 in. diameter holes placed in a fairing similar to the array fairing. This source produced usable levels from 2 to $100 \mathrm{kHz}$ and was approximately omnidirectional over the emission angle range of $45^{\circ}$ to $135^{\circ}$ and azimuth angle range of $+/$ $45^{\circ}$ as measured in the anechoic chamber. The usable frequency range of this source is currently being extended down to $300 \mathrm{~Hz}$ by adding a broadband driver to the fairing.

For the four configurations, the background levels and array conventional beamform peak levels at $92^{\circ}$ emission angle were comparable to about $30 \mathrm{kHz}$. The out-of-flow array response fell off relative to the in-flow for higher frequencies by $7-8 \mathrm{~dB}$ at $95 \mathrm{kHz}$. At higher emission angles, the out-of-flow array response began to fall-off relative to the in-flow arrays at lower frequencies and to a greater degree than for $92^{\circ}$. The high-frequency response roll-off is presumably due to greater scattering of the target source acoustic waves through the thicker boundary- and shearlayers of the out-of-flow arrays. The response characteristics were steady and repeatable and could form the basis of 
a frequency dependent correction as a function of emission angle and mounting configuration for a particular facility.

The array and acoustic calibration sources were designed as a candidate reference sensor and acoustic source for improving the accuracy of aeroacoustic research testing at NASA's Ames, Glenn, and Langley Research Centers. Further experimental assessments are in progress at the three centers, as well as efforts to increase the operational bandwidth of the in-flow array and calibration sources. Success in these efforts are anticipated to improve the accuracy and repeatability of aeroacoustic research and enable meaningful comparisons between measurements obtained in the various test facilities. Further studies are planned or in progress will examine the effectiveness of various approaches to improve level measurement accuracy, sensor bandwidth and signal to noise ratio. These include advanced beamform processing with cross-spectral-matrix background noise subtraction, increased source bandwidth (particularly at low frequencies), increased array bandwidth, and optimal wind screen design.

\section{Acknowledgements}

This research was supported by NASA's Aeronautical Research Mission Directorate Advanced Air Transport Technology program. Significant contributions to this project were provided by development team members Gary Podboy (NASA Glenn Research Center), Christopher Bahr and Tony Humphreys (NASA Langley Research Center) who are evaluating the sensor and source fairings in their aeroacoustic research facilities. The authors appreciate the substantial assistance provided by Dr. Ben Sim and the operations staff at the Army 7- by 10-ft Wind Tunnel at NASA Ames, as well as technical support from Stephen Schery, Bethany White and David Kiel at the Experimental Aerophysics Branch at NASA Ames. The in-flow array fairing design was originally developed by Robert Mosher, currently at NASA Langley Research Center.

\section{References:}

1. Humphreys, W. et al "Design and Use of Microphone Directional Arrays for Aeroacoustic Measurements," AIAA-1998-471, 36th AIAA Aerospace Sciences Meeting and Exhibit, Jan. 12-15, 1998, Reno, NV.

2. Horne, W., and Burnside, N., "Development of New Wall-mounted and Strut-mounted Phased Microphone Arrays for Acoustic Measurements in Closed Test-section Wind Tunnels", AIAA-2015-2975, AIAA/CEAS $21^{\text {st }}$ Aeroacoustics Conf., June 22-26, 2015, Dallas, TX.

3. Underbrink, J., "Pletharrays for Aeroacoustic Phased Array Applications", AIAA-2015-2978, AIAA/CEAS $21^{\text {st }}$ Aeroacoustics Conf., June 22-26, 2015, Dallas, TX.

4. Schmitz, F., Liu, S., Jaeger, S., and Horne, W., "Noise reducing screen devices for in-flow pressure sensors", US5684756 A, November 4, 1997.

5. Horne, W.C, and James, K.D., "Concepts for Reducing the Self-noise of In-flow Acoustic Sensors and Arrays", AIAA-99-1815, AIAA 5th Aeroacoustics Conf. and Exhibit, June 1999, Bellevue, WA

6. Jaeger, S.M., Horne, W.C., and Allen, C.S., "Effect of Surface Treatment on Array Microphone Self-Noise," AIAA-2000-1937, 6th AIAA/CEAS Aeroacoustics Conf. and Exhibit, June 12-14, 2000, Lahaina, NV.

7. Fleury, V., Coste, L., Davy, R., Mignosi, A., Cariou, C., and Prosper, J.M., "Optimization of Microphone Array Wall Mountings in Closed-Section Wind Tunnels", AIAA J., vol. 50, no.11, Nov., 2012.

8. Blacodon, D., "Array Processing for Noisy Data: Application for Open and Closed Wind Tunnels", AIAA J., vol. 49, no. 1, Jan. 2011.

9. Bahr, C.J., and Horne, W.C., "Advanced Background Subtraction Applied to Aeroacoustic Wind Tunnel Testing", AIAA-2015-3272, $21^{\text {st }}$ AIAA/CEAS Aeroacoustics Conf., 22-26 June , 2015, Dallas, TX.

10. Pires, L.S., Dougherty, R.P., Gerges, S.N.Y., and Catalano, F., "Predicting Turbulent Decorrelation in Acoustic Phased Array," AIAA-2012-0387, 50th AIAA Aerospace Sciences Meeting, Jan. 9-12, 2012, Nashville, TN.

11. Krober, S., Ehrenfried, K., Koop, L., Laterbach, A., and Henning, A., “ Systematic Comparison of Microphone 
Array Measurements in Open and Closed Wind Tunnels", AIAA-2010-3734, 16 ${ }^{\text {th }}$ AIAA/CEAS Aeroacoustics Conference, June 7-9, 2010, Stockholm, Sweden.

12. Podboy, Gary, NASA Glenn Research Center, private communication 2016.

13. Panda, J., Mosher, R., and Porter, B., "Noise Source Identification During Rocket Engine Test Firings and a Rocket Launch", Journal of Spacecraft and Rockets, 2014, Vol.51: 1761-1772, 10.2514/1.A32863 

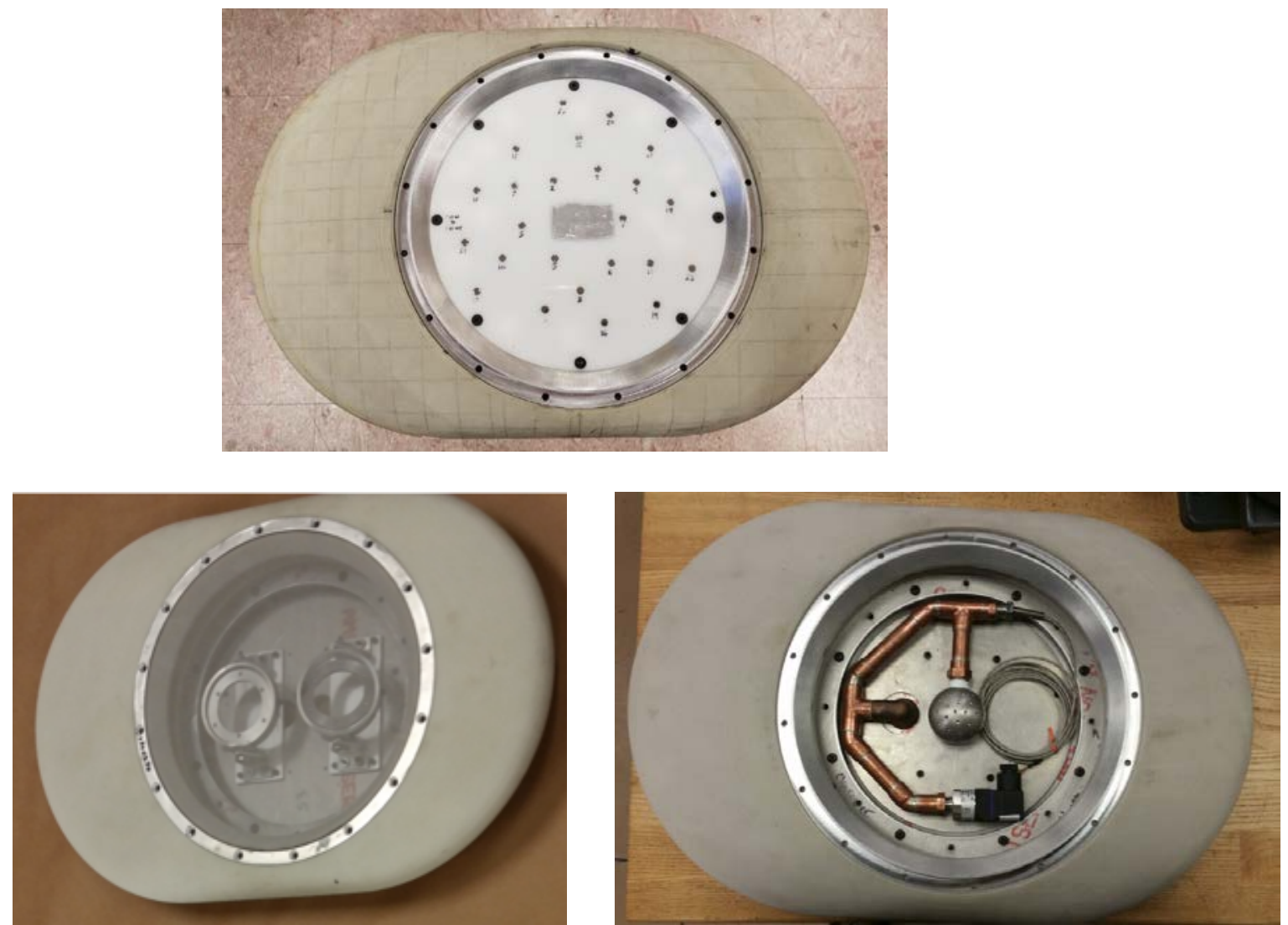

Fig. 1 In-flow fairings with 24 microphone array plate (top), dual tweeters (lower left), and 2" diam. airball with 44 0.035 " diam. holes (lower right). A 3" diam. hemispheric screen cover over the airball is removed for the left photo. The fairing leading edge is to the right for each configuration.

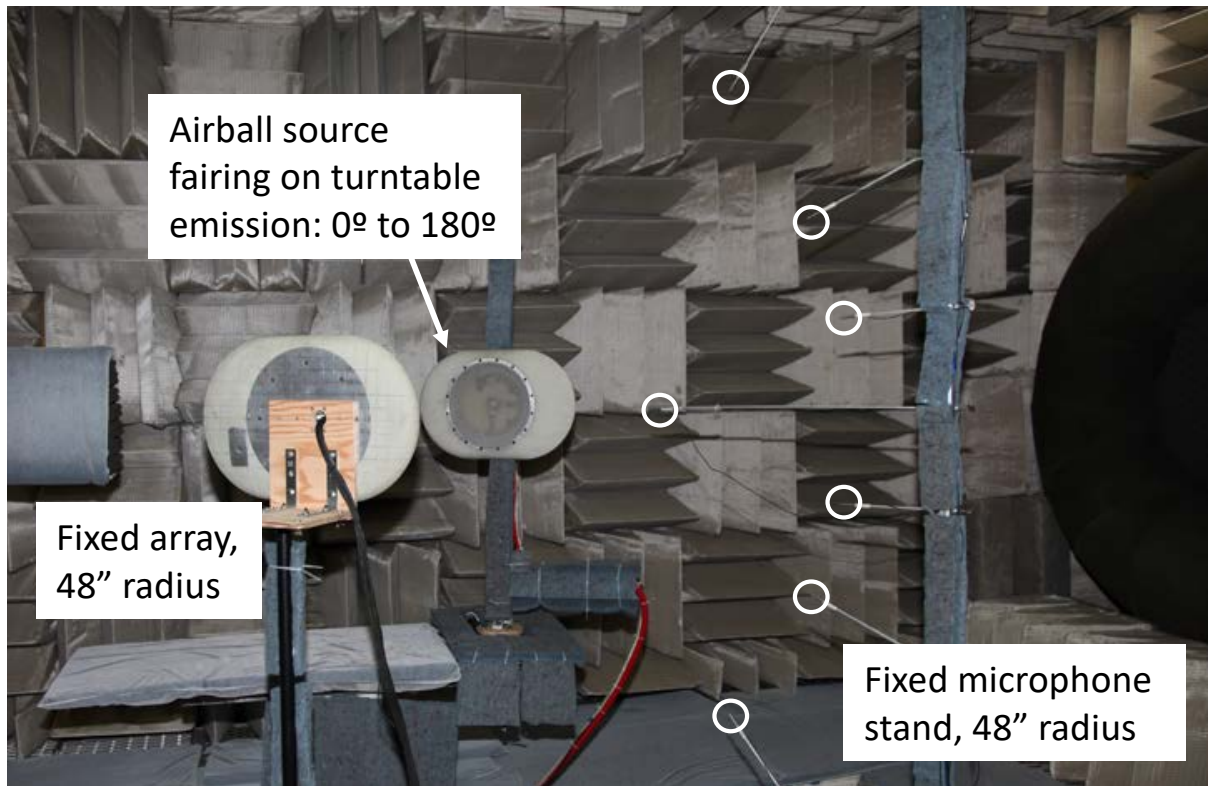

Fig. 2 Airball source fairing on turntable, fixed microphone stand, and fixed array in anechoic chamber calibration setup. Note that the $0^{\circ}$ azimuth microphone has a radius of 24 " in this photo. 

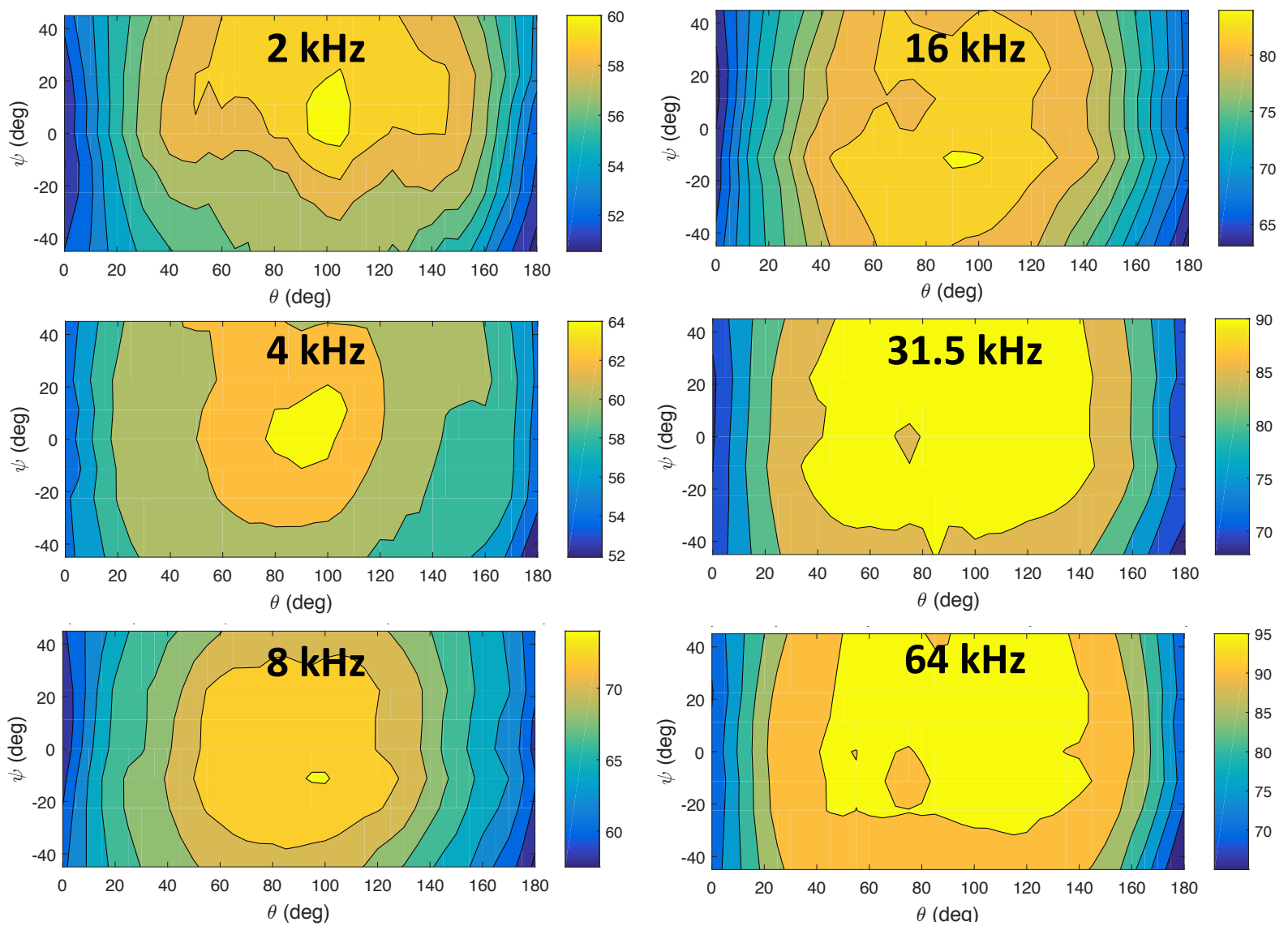

Fig. 3 Contour maps of the airball source directivity levels (in $\mathrm{dB}$ re $20 \mu \mathrm{Pa}$ ) at $\sim 17$ psig supply pressure at selected $1 / 3$-octave bands. Emission angle, $\theta$ ' is plotted on the horizontal axes and azimuthal angle, $\Psi$ is on the vertical axis. 


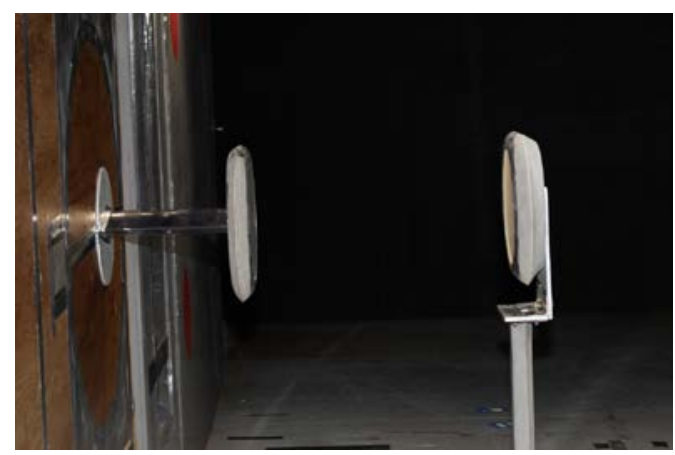

a) Strut mount array, looking upstream

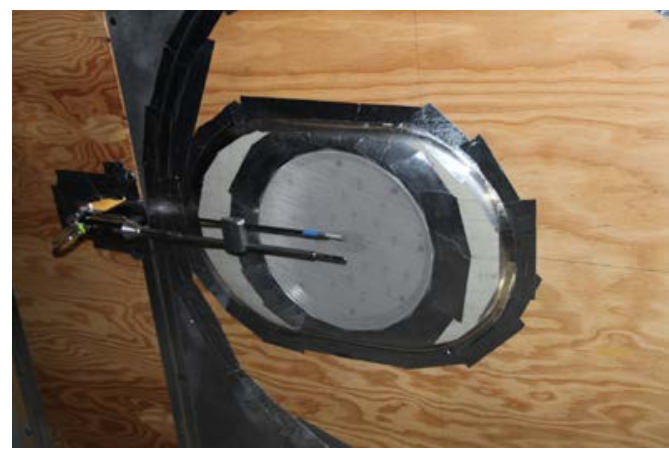

b) Wall mount with velocity survey probes

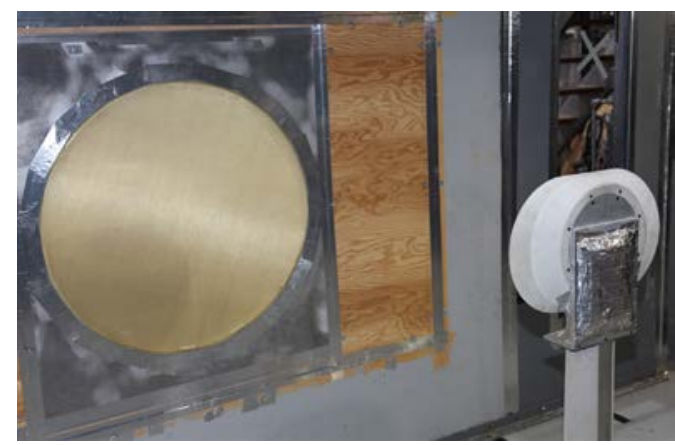

c) Kevlar wall screen, view from inside tunnel

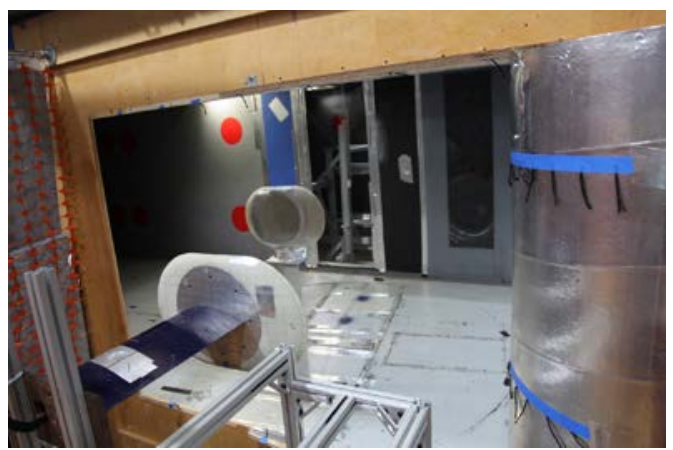

d) Array 10" outside of free shear-layer, with collector to the right

Fig. 4 Setup in US Army 7- by 10-Ft Wind Tunnel at NASA Ames Research Center.
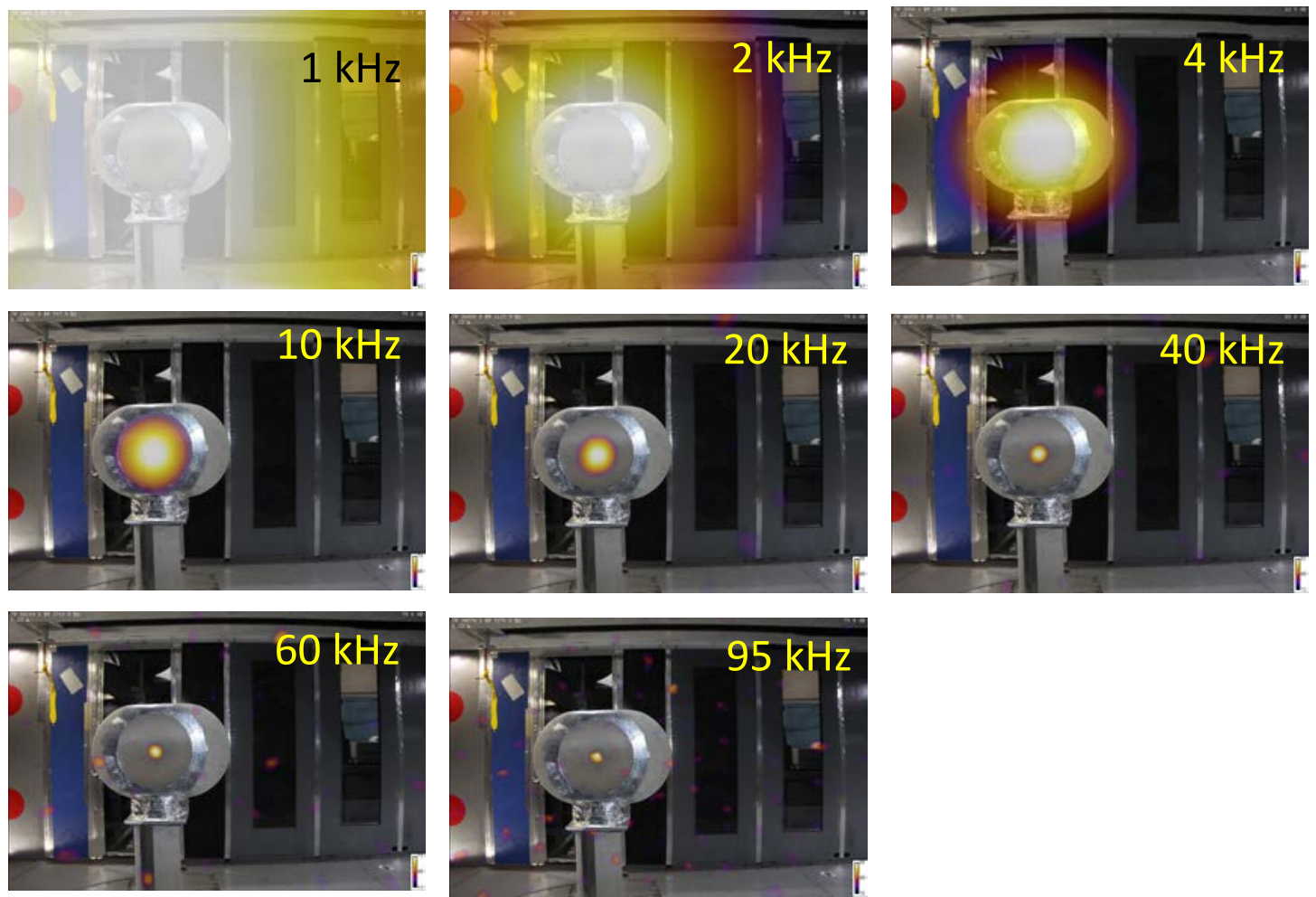

Fig. 5 Conventional beamform maps for the airball source in the wind tunnel at $\mathrm{M}=0$. 


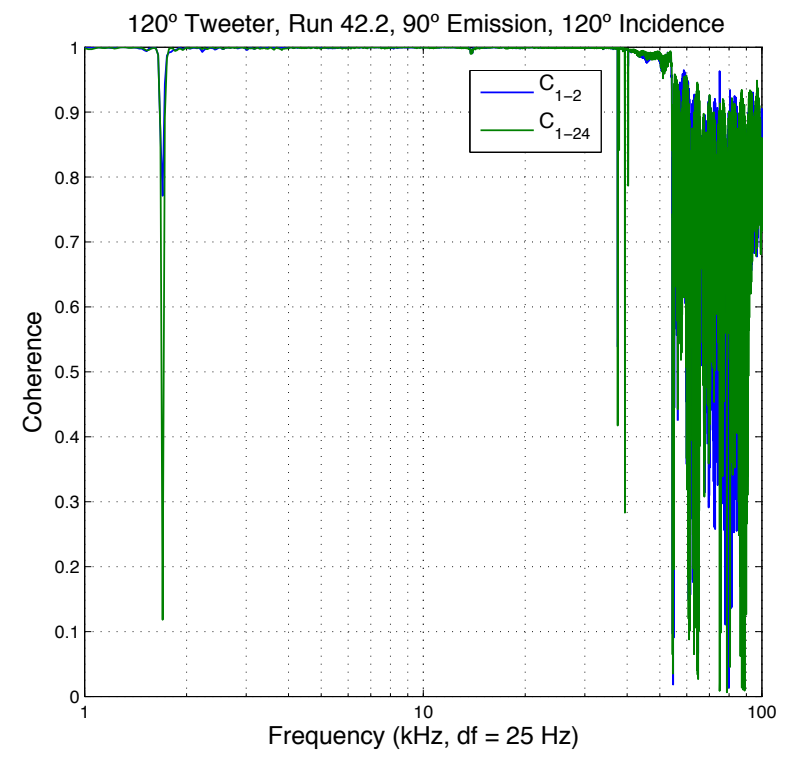

a) Tweeter source

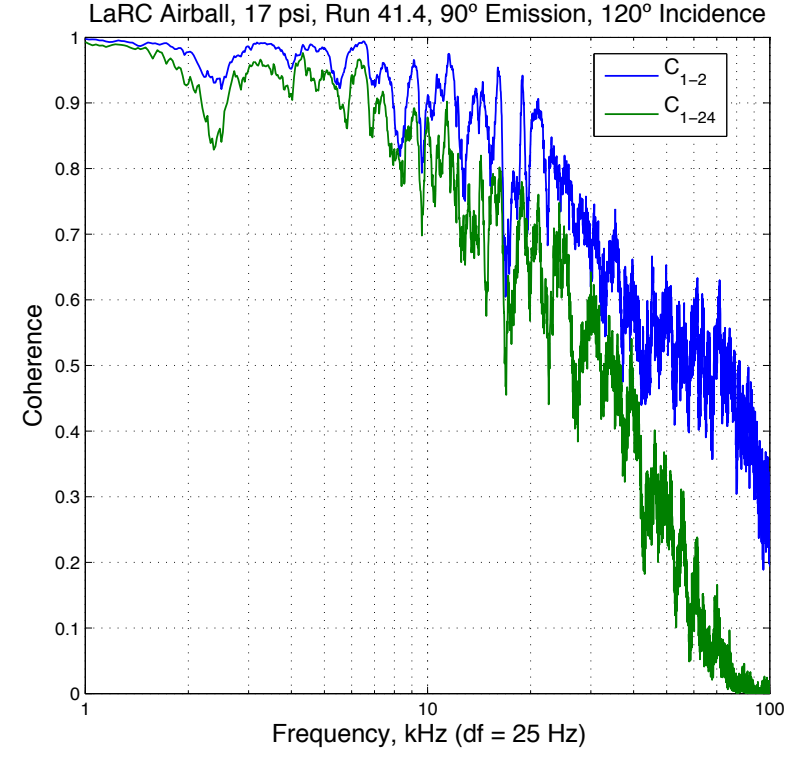

b) Airball source

Fig. 6. Anechoic chamber comparison of coherence between closely space microphones 1 and 2 (blue), and widely spaced microphones 1 and 24 (green).

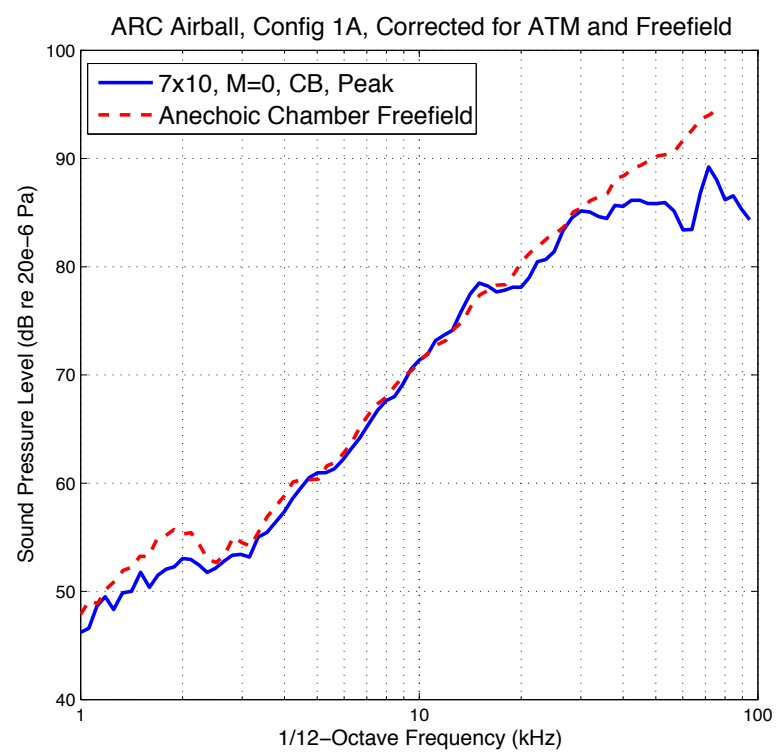

a) Wind tunnel $\mathrm{M}=0, \theta^{\prime}=100^{\circ}$

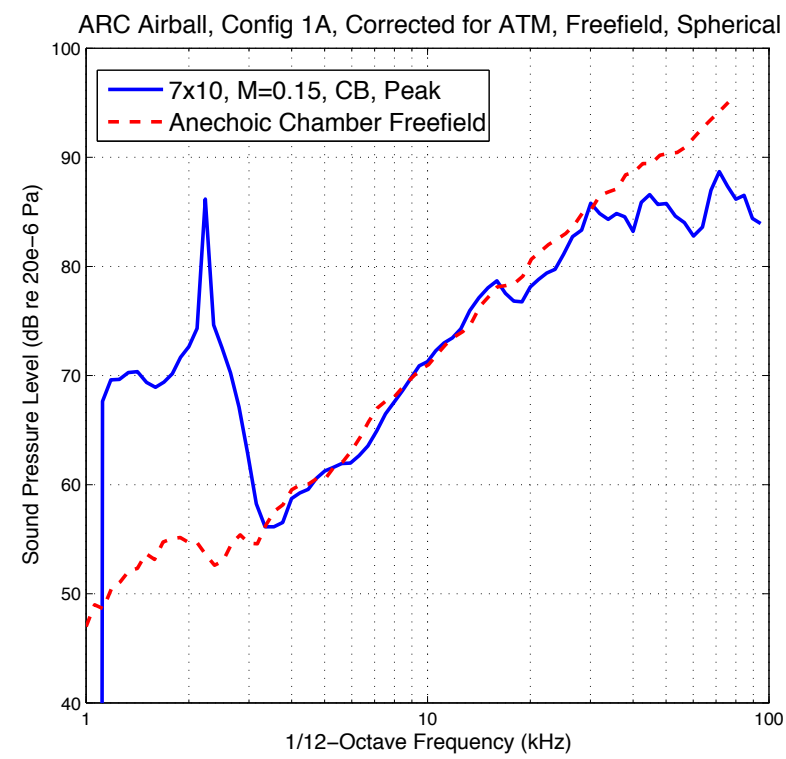

b) Wind tunnel $\mathrm{M}=0.15, \theta^{\prime}=92^{\circ}$

Fig. 7. Comparison of anechoic chamber (red) and wind tunnel (blue) $1 / 12^{\text {th }}$-ocatave spectra (conventional beamform peak) for the strut-mounted hemispheric multijet source at $\mathrm{P} \sim 17 \mathrm{psig}, \mathrm{y}=28$ in. 


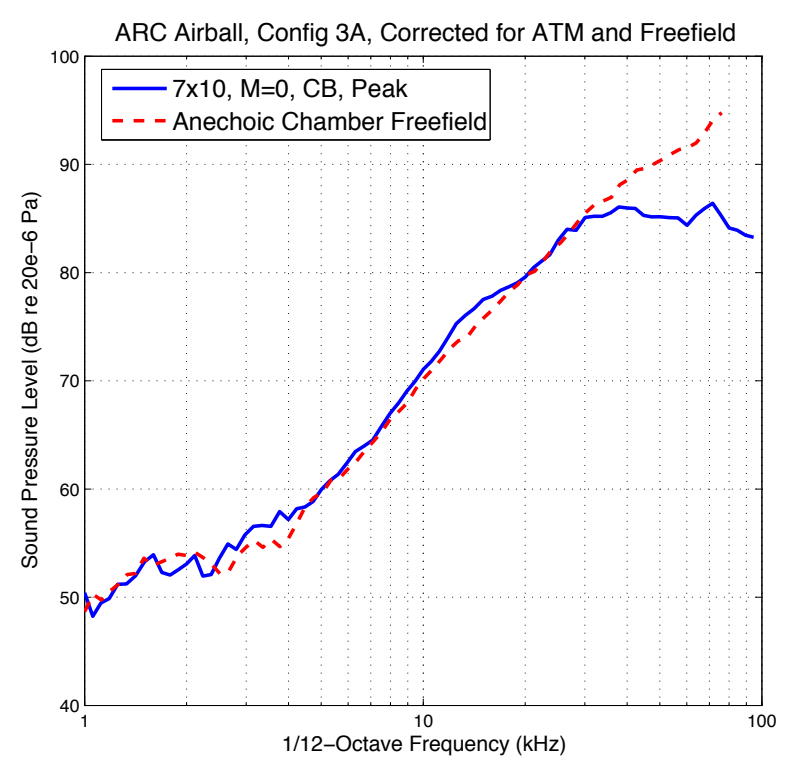

a) Wind tunnel $\mathrm{M}=0, \theta^{\prime}=125^{\circ}$

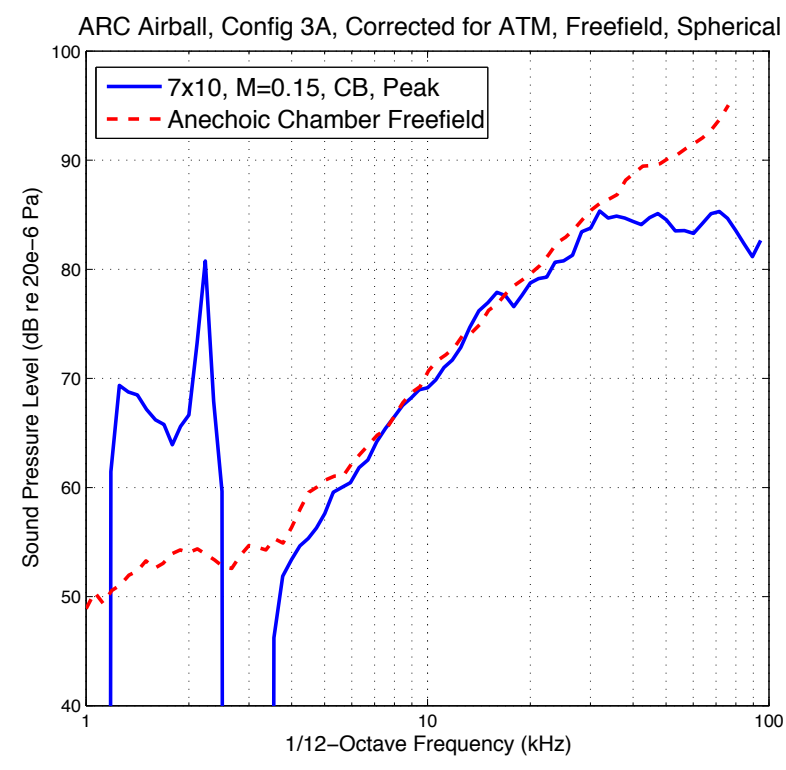

b) Wind tunnel $\mathrm{M}=0.15, \theta^{\prime}=125^{\circ}$

Fig. 8 Comparison of anechoic chamber (red) and wind tunnel (blue) $1 / 12^{\text {th }}$-ocatave spectra (conventional beamform peak) for the strut-mounted airball source at $\mathrm{P}=16.5 \mathrm{psig}$. 


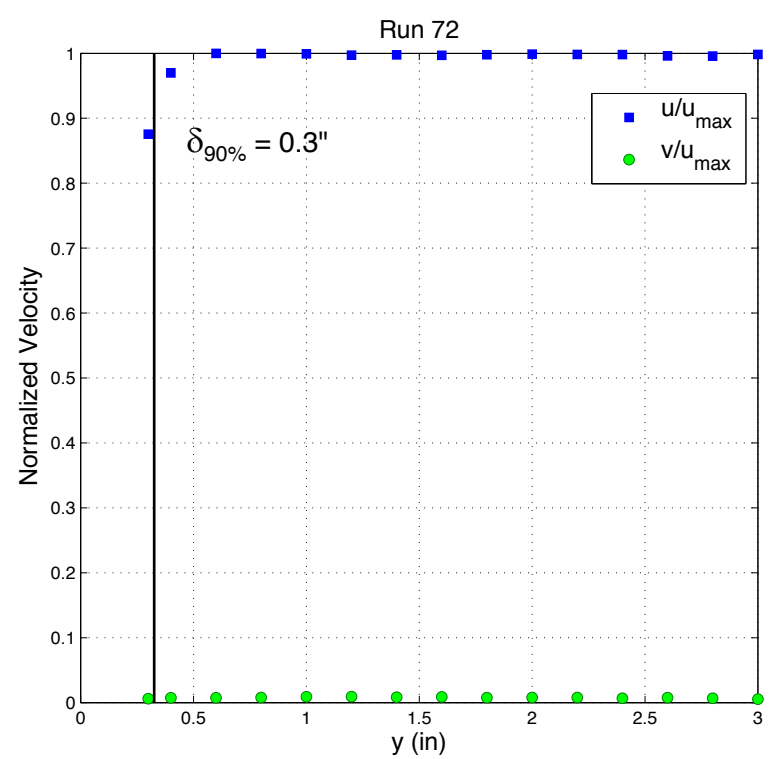

a) Strut mount

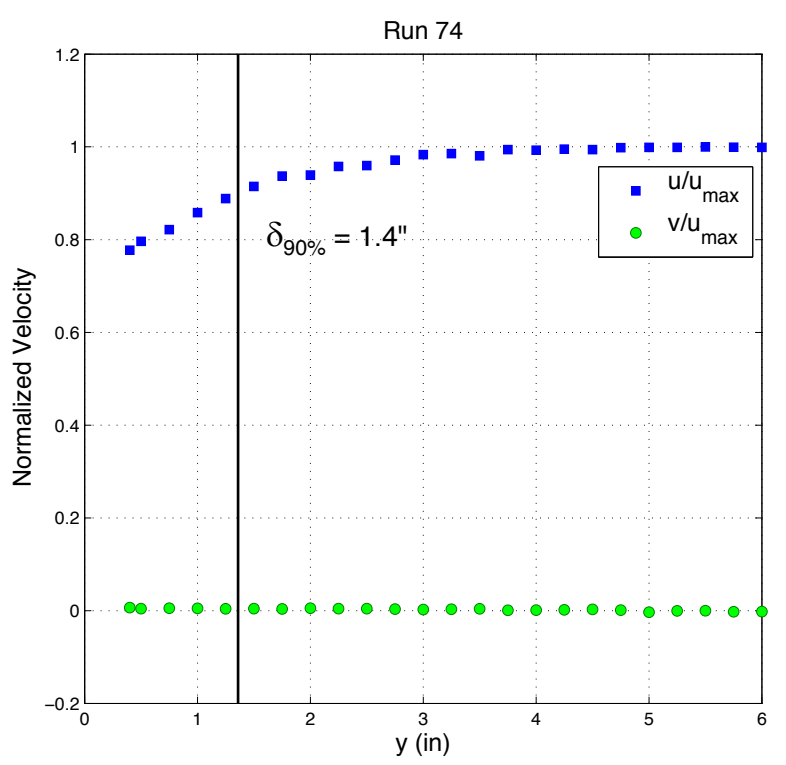

b) Wall mount

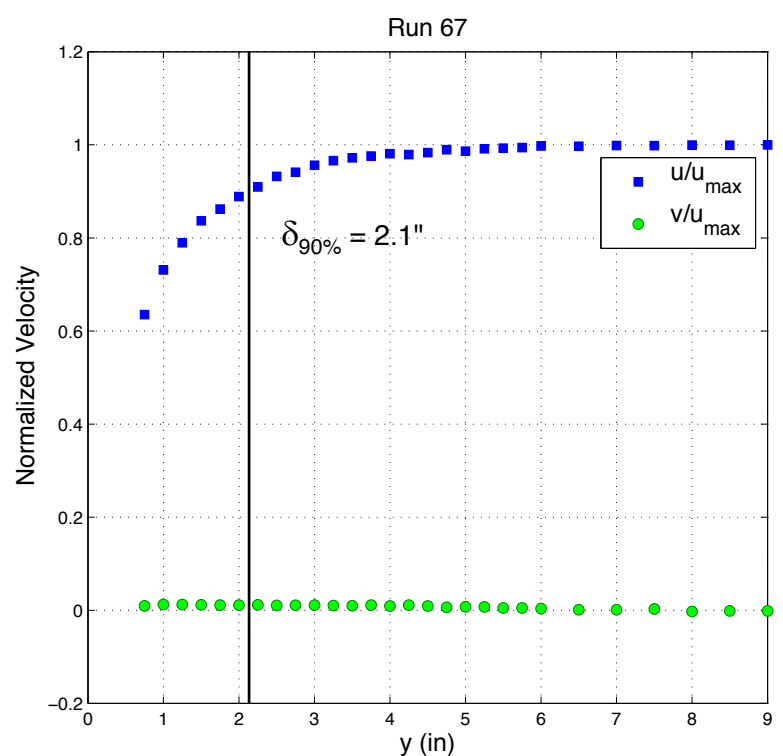

c) Kevlar screen

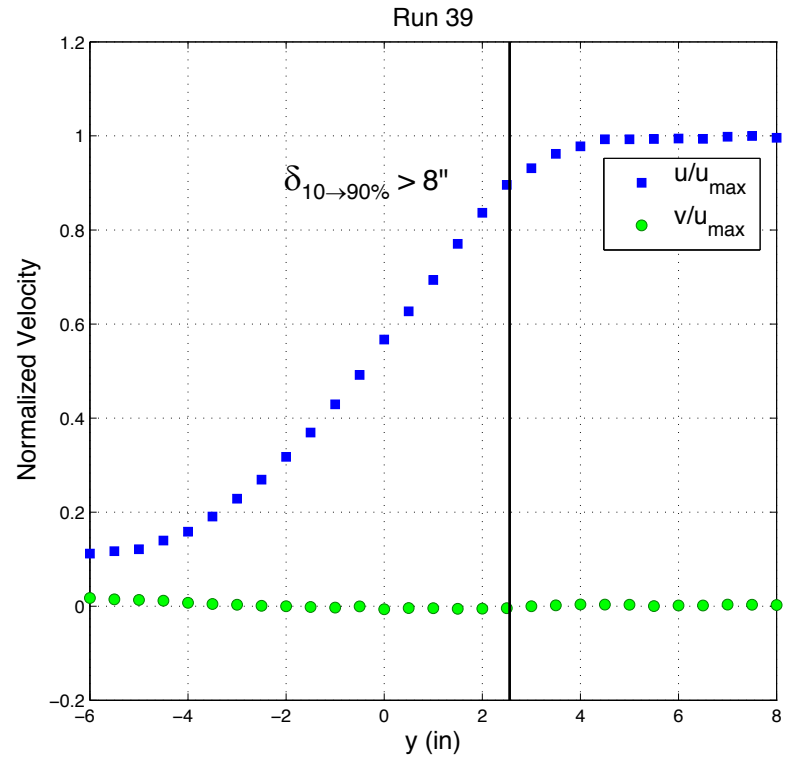

d) Free shear layer

Fig. 9 Mean velocity profiles and $0.9^{*} \mathrm{U}_{\mathrm{FS}}$ shear layer thicknesses for nominal $120^{\circ}$ position. Streamwise component plotted in blue and cross-stream plotted in green. 


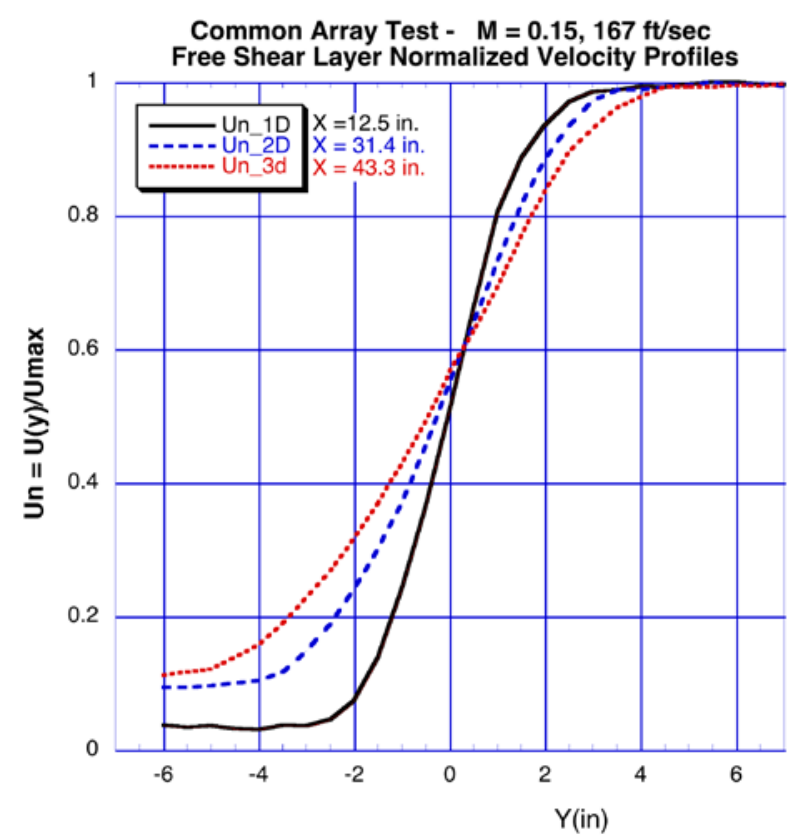

a) Velocity profiles

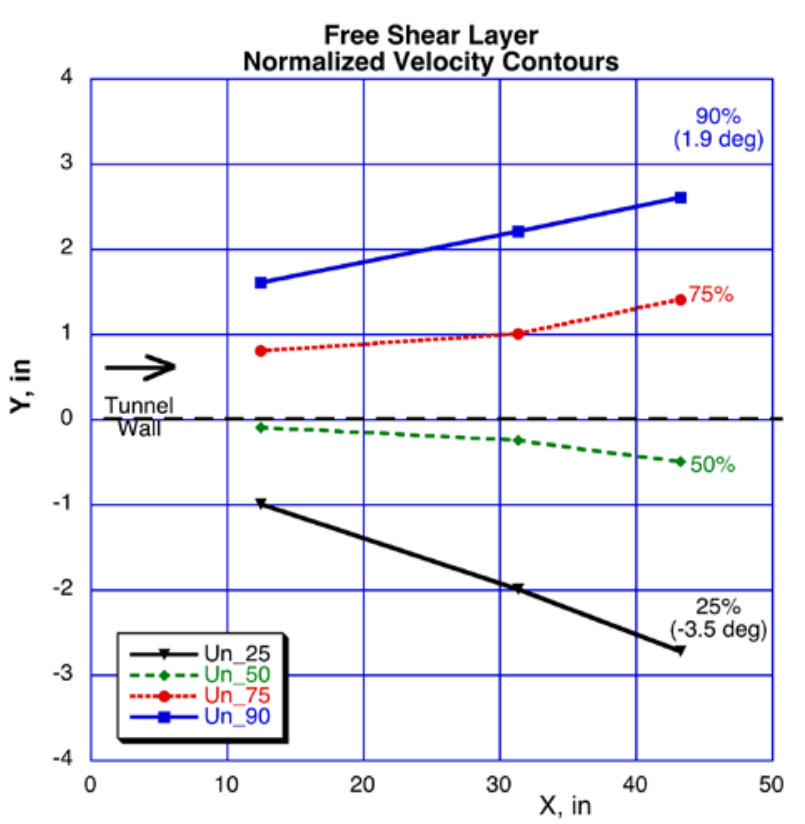

b) Velocity contours

Fig. 10 Free shear layer velocity profiles and contours for array positions $92^{\circ}, 108^{\circ}$, and $120^{\circ}$. 


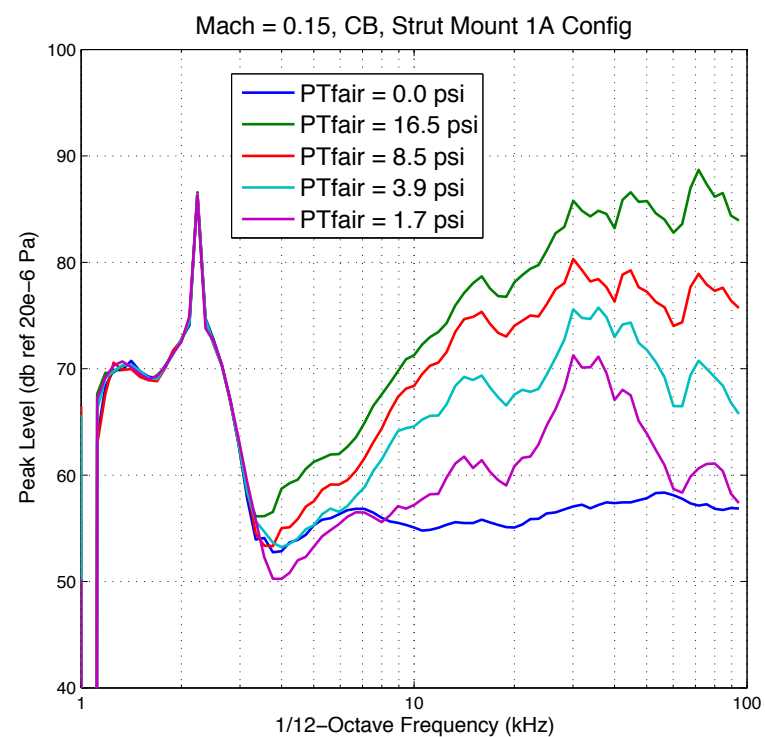

a) Strut mounted array

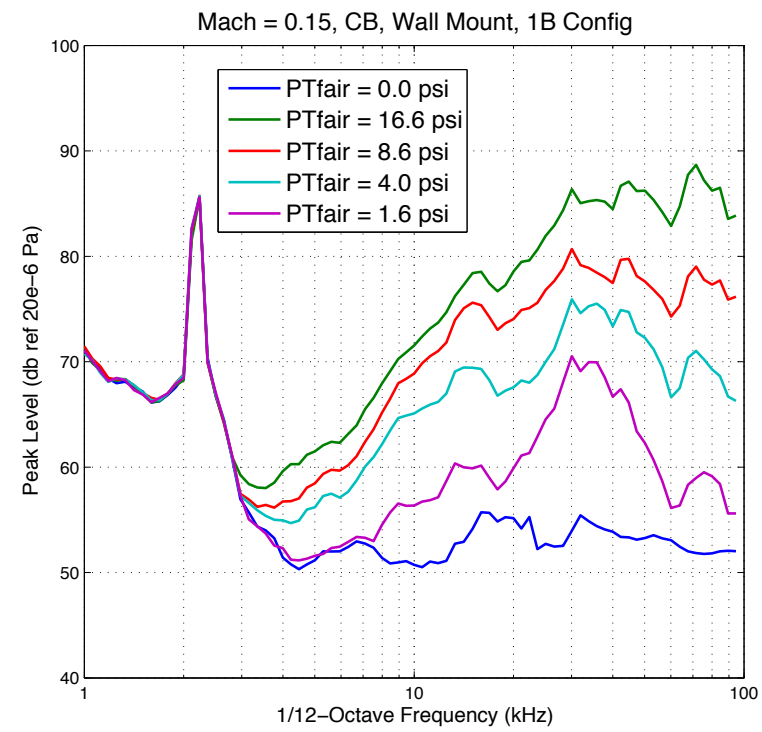

b) Wall mounted array

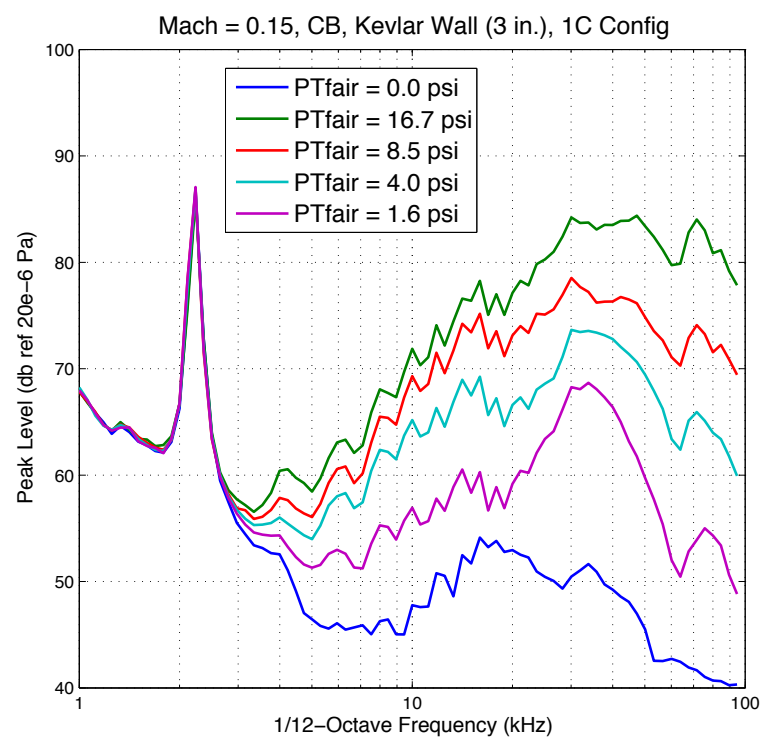

c) Array recessed 3" behind porous Kevlar

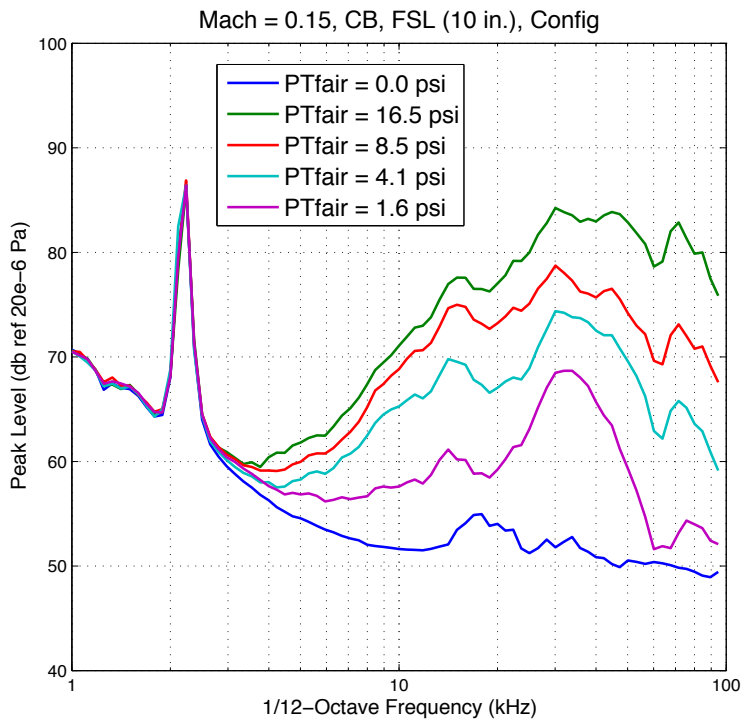

d) Array recessed 10" behind free shear layer

Fig. 11. Comparison of $1 / 12^{\text {th }}$-octave conventional beamforming peak array levels of airball source for five supply pressures between 0 and 16.5 psig at $\mathrm{M}=0.15, \theta^{\prime}=92^{\circ}$. 


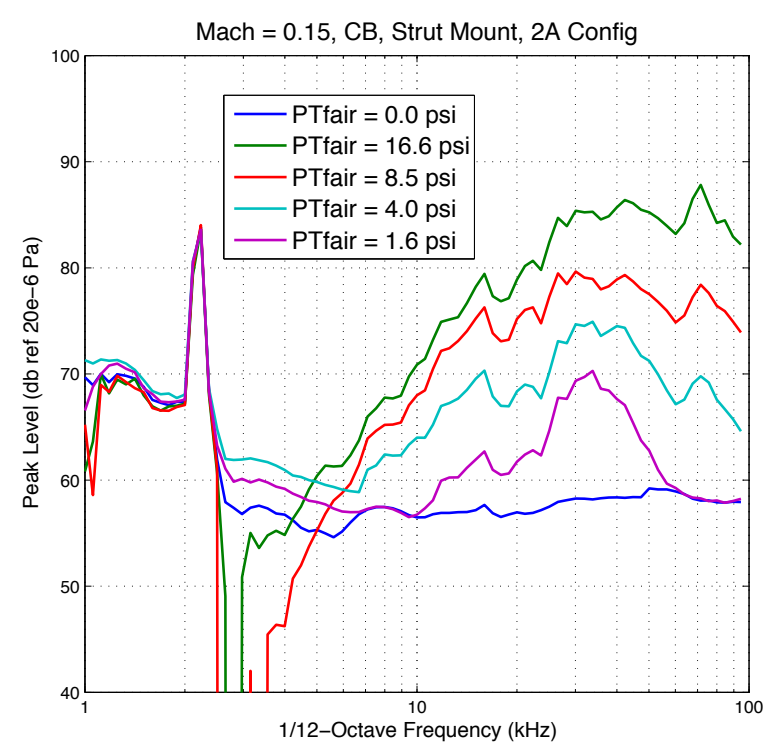

a) Strut mounted array

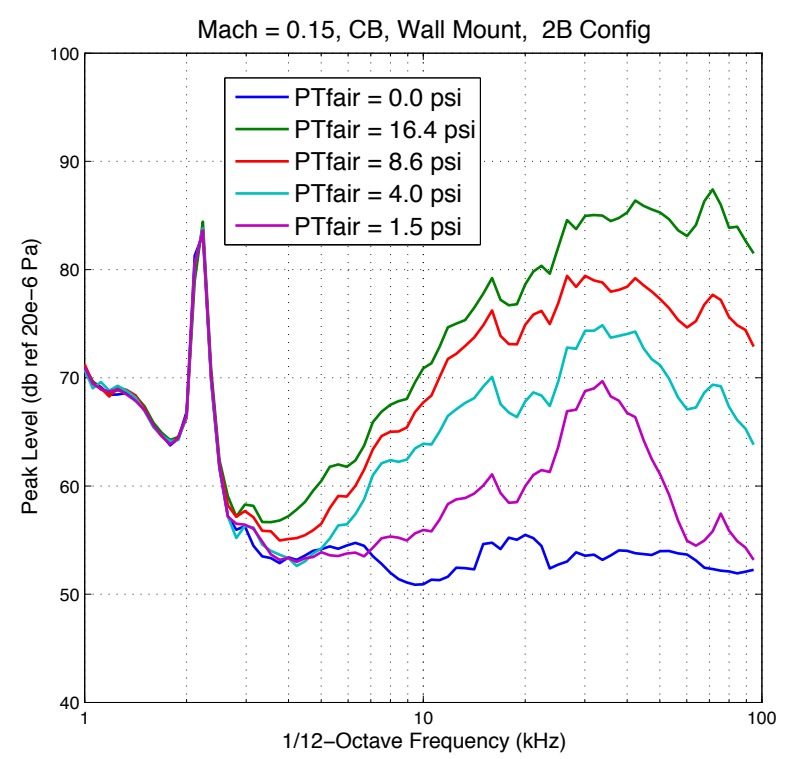

b) Wall mounted array

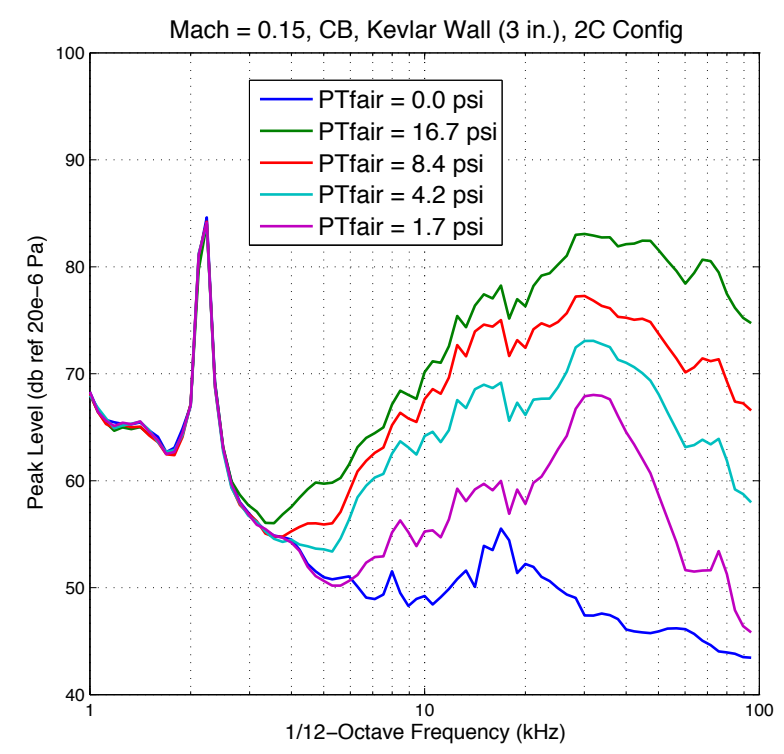

c) Array recessed 3" behind porous Kevlar

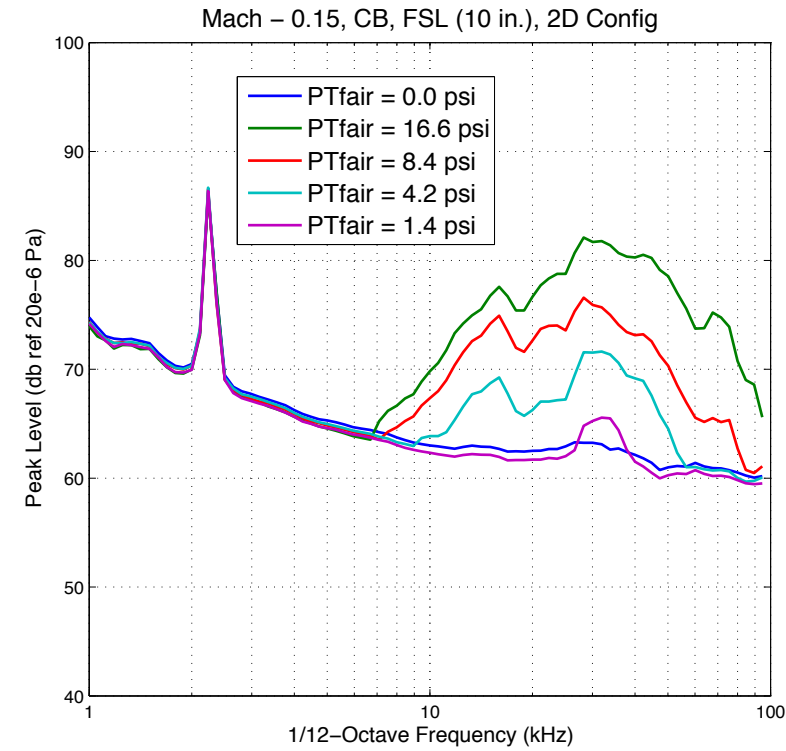

d) Array recessed 10" behind free shear layer

Fig. 12. Comparison of $1 / 12^{\text {th }}$-octave conventional beamforming peak array levels of airball source for five supply pressures between 0 and $16.5 \mathrm{psig}$ at $\mathrm{M}=0.15, \theta^{\prime}=108^{\circ}$. 


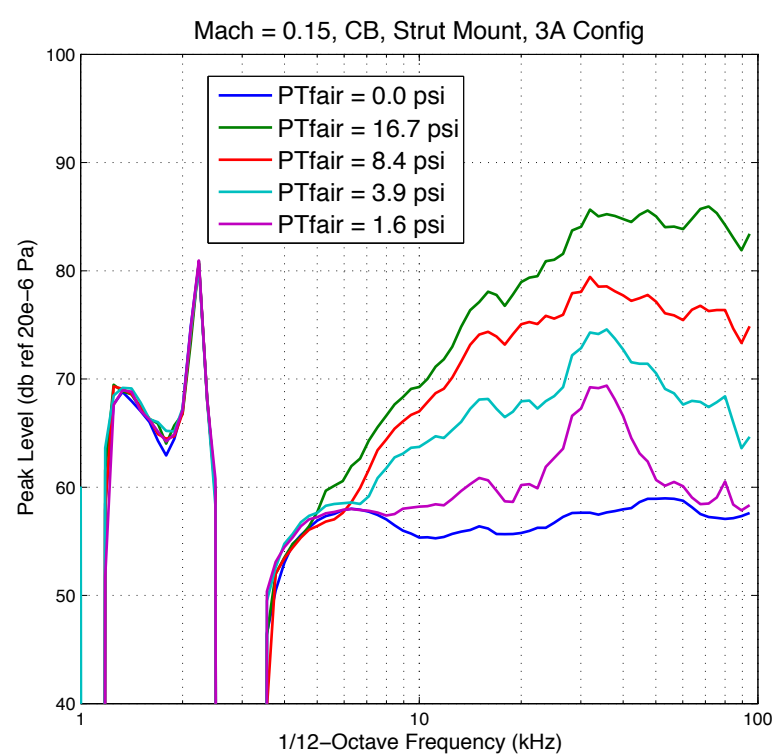

a) Strut mounted array

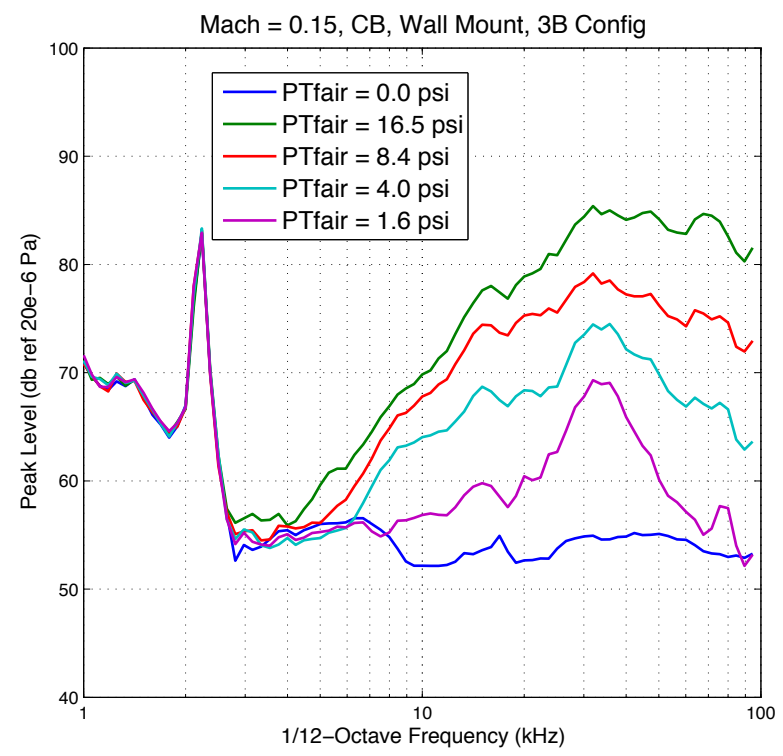

b) Wall mounted array

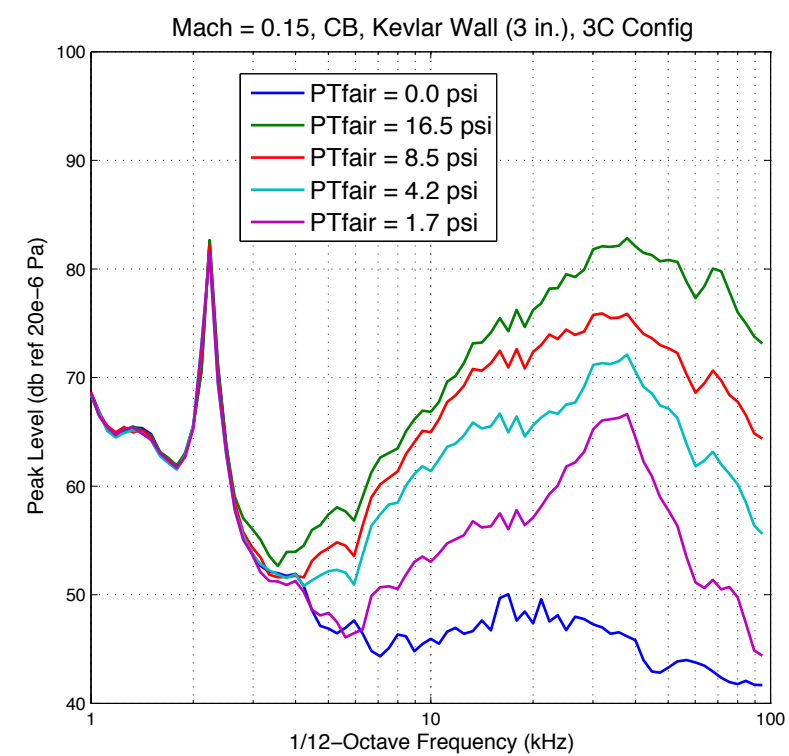

c) Array recessed 3" behind porous Kevlar

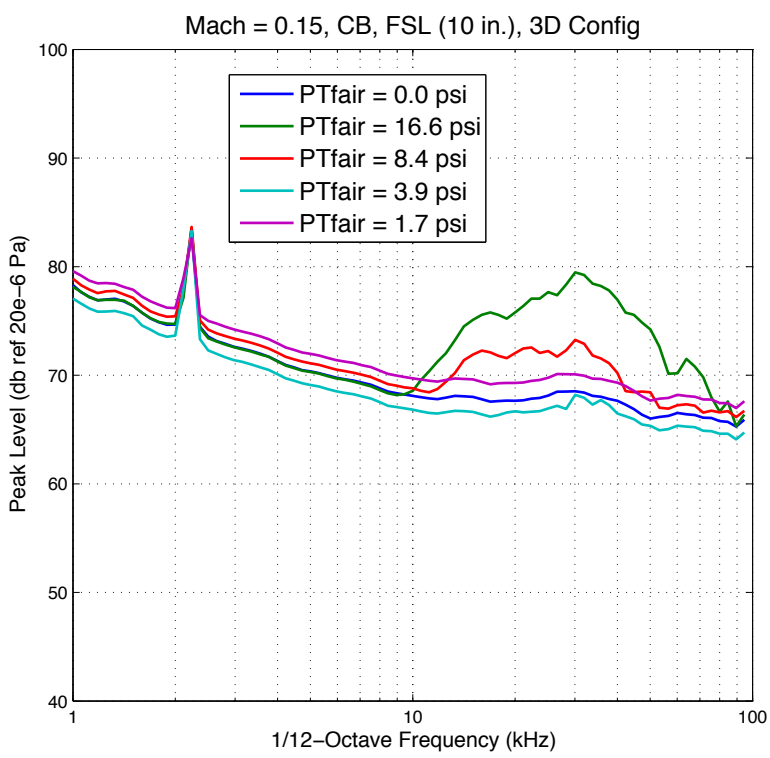

d) Array recessed 10" behind free shear layer

Fig. 13. Comparison of $1 / 12^{\text {th }}$-octave conventional beamforming peak array levels of airball source for five supply pressures between 0 and $16.5 \mathrm{psig}$ at $\mathrm{M}=0.15, \theta^{\prime}=120^{\circ}$. 


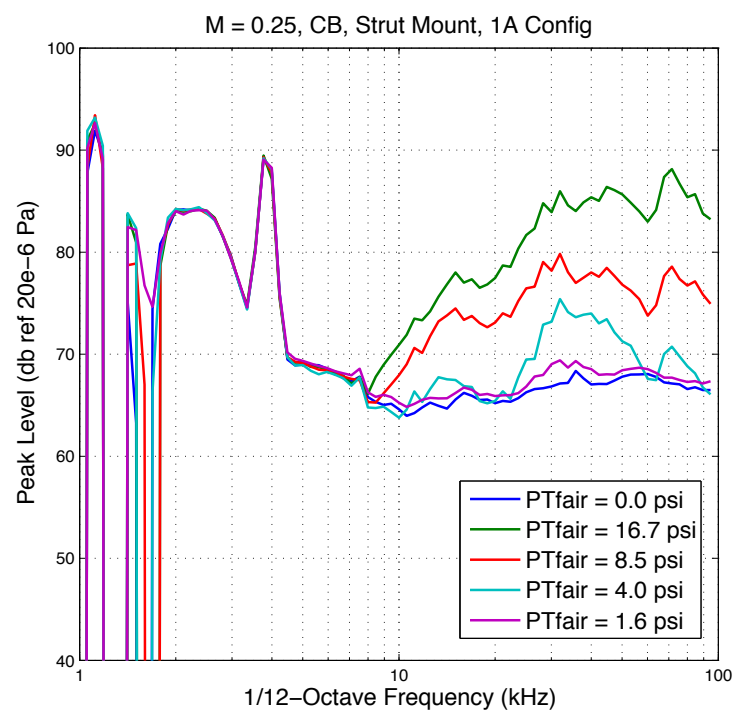

a) Strut mounted array

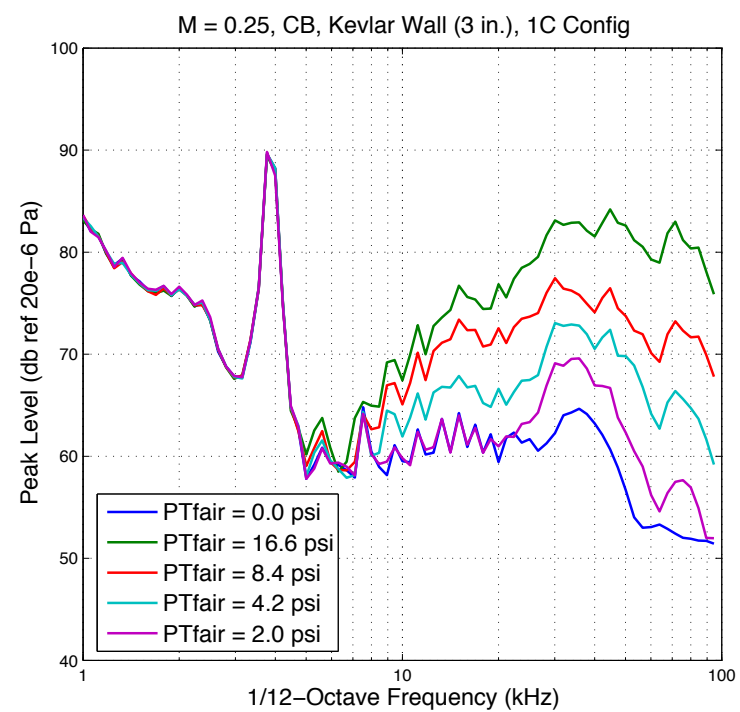

c) Array recessed 3" behind porous Kevlar

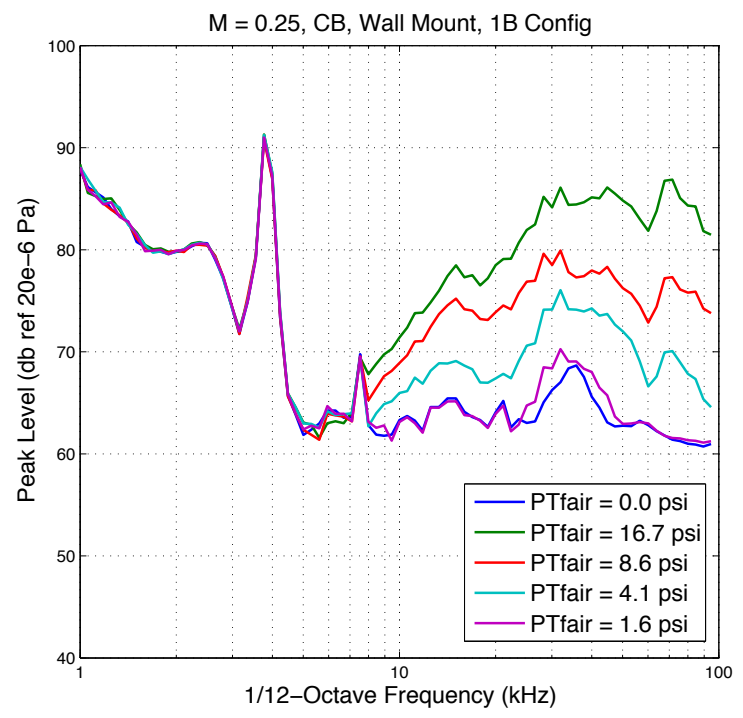

b) Wall mounted array

Fig. 14. Comparison of $1 / 12^{\text {th }}$-octave conventional beamforming peak array levels of airball source for five supply pressures between 0 and $16.5 \mathrm{psig}$ at $\mathrm{M}=0.25, \theta^{\prime}=92^{\circ}$. 


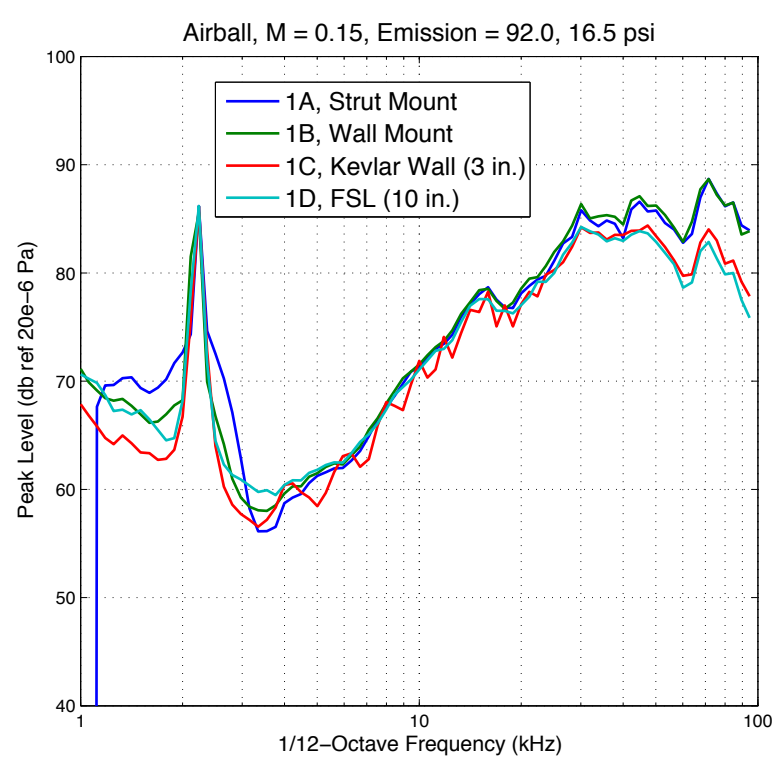

a) nominal $\theta^{\prime}=92^{\circ}$

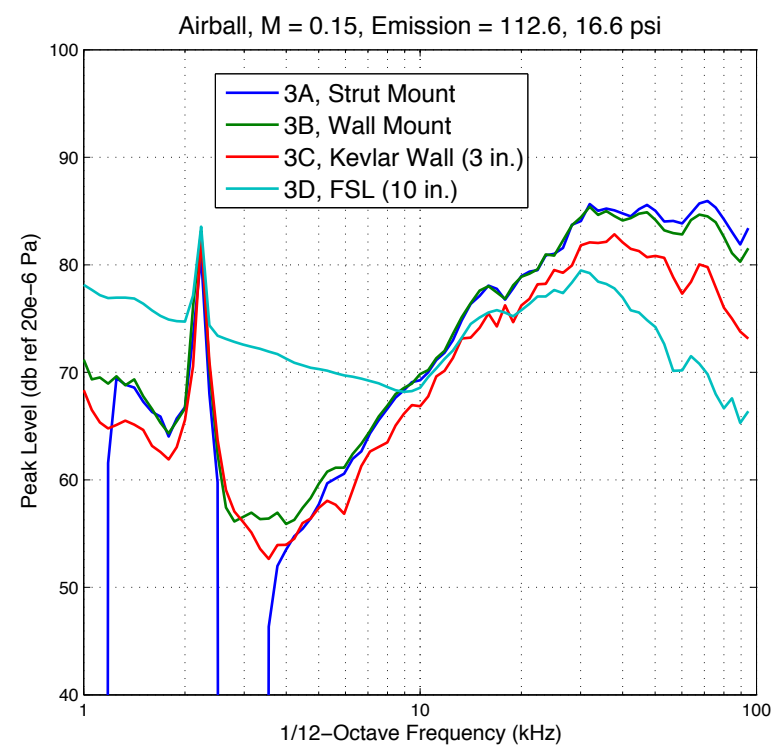

c) nominal $\theta^{\prime}=120^{\circ}$

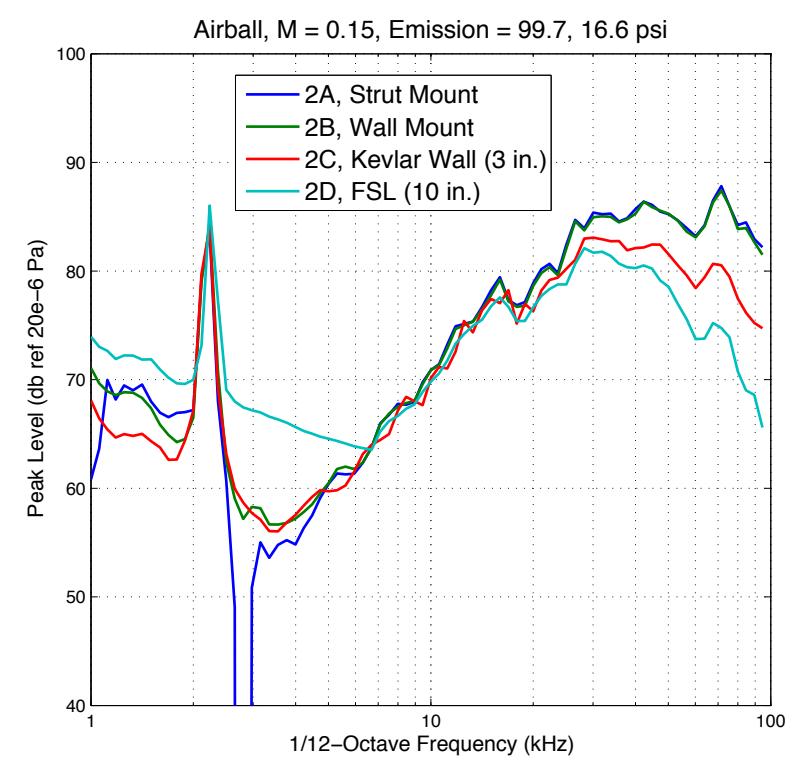

b) nominal $\theta^{\prime}=108^{\circ}$

Fig. 15. Comparison of $1 / 12^{\text {th }}$-octave conventional beamforming peak array levels of airball source at supply pressure of 16.5 psig at $\mathrm{M}=0.15$ for the four installation configurations. 


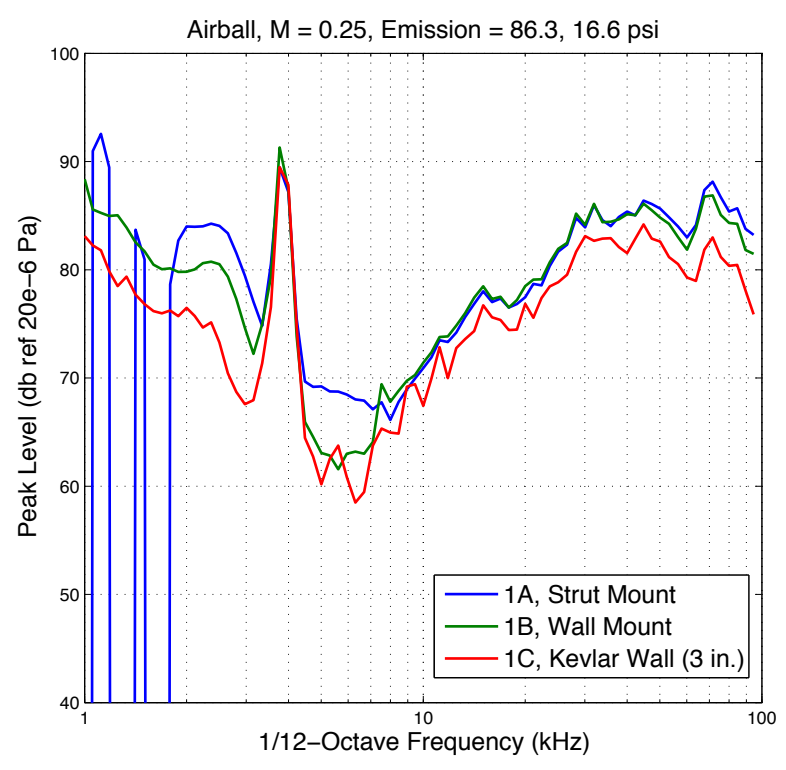

a) nominal $\theta^{\prime}=92^{\circ}$

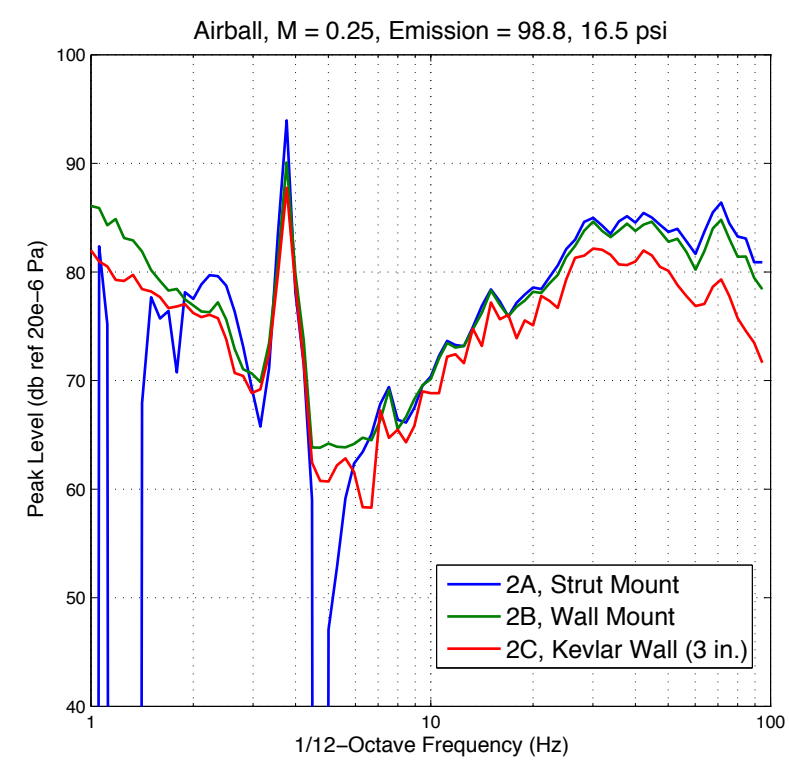

b) nominal $\theta^{\prime}=108^{\circ}$

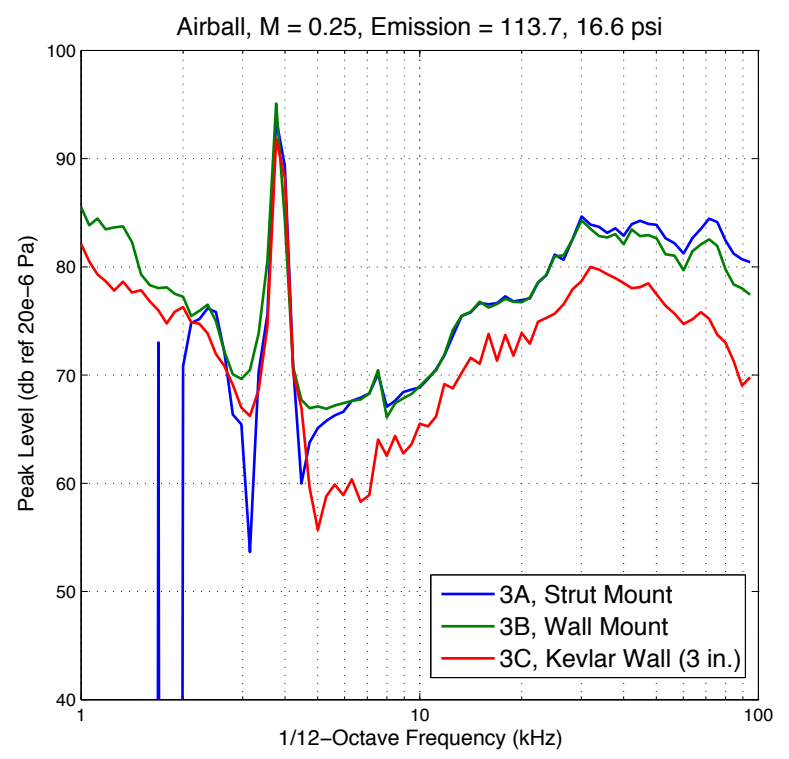

c) nominal $\theta^{\prime}=120^{\circ}$

Fig. 16. Comparison of $1 / 12^{\text {th }}$-octave conventional beamforming peak array levels of airball source at supple pressure of 16.5 psig at $\mathrm{M}=0.25$ for the four installation configurations. 


\begin{tabular}{|c|c|c|c|c|c|}
\hline Position & $\mathrm{X}$, in & $\mathrm{Y}$, in & Position & $\mathrm{X}$, in & $\mathrm{Y}$, in \\
\hline 1 & 1.500 & 0.000 & 13 & -1.090 & -2.940 \\
\hline 2 & -0.750 & 1.300 & 14 & 3.090 & 0.525 \\
\hline 3 & -0.750 & -1.300 & 15 & -2.000 & 2.415 \\
\hline 4 & 0.730 & 1.675 & 16 & 0.800 & -3.370 \\
\hline 5 & -1.815 & -0.207 & 17 & 2.520 & 2.375 \\
\hline 6 & 1.085 & -1.465 & 18 & -3.315 & 0.995 \\
\hline 7 & -2.055 & 1.130 & 19 & 2.490 & -2.820 \\
\hline 8 & 0.051 & -2.345 & 20 & 1.200 & 3.565 \\
\hline 9 & 2.005 & 1.215 & 21 & -3.685 & -0.745 \\
\hline 10 & -2.455 & -1.275 & 22 & 3.675 & -1.675 \\
\hline 11 & 2.335 & -1.490 & 23 & -0.390 & 4.020 \\
\hline 12 & 0.122 & 2.765 & 24 & -3.285 & -2.345 \\
\hline
\end{tabular}

Table 1. Corrected microphone positions for 8 " diameter array. A central microphone at $[0,0]$ may be added as a single microphone reference.

(The values originally published were twice the actual numbers) 